\title{
Peroxide-Induced Synthesis of Maleic Anhydride-Grafted Poly(butylene succinate) and Its Compatibilizing Effect on Poly(butylene succinate)/Pistachio Shell Flour Composites
}

\author{
Sandra Rojas-Lema ${ }^{1, * \mathbb{D}}$, Jordi Arevalo ${ }^{1}$, Jaume Gomez-Caturla ${ }^{1} \mathbb{D}$, Daniel Garcia-Garcia ${ }^{1} \mathbb{D}$ and \\ Sergio Torres-Giner ${ }^{2} *$ (D) \\ 1 Technological Institute of Materials (ITM), Universitat Politècnica de València (UPV), Plaza Ferrándiz y \\ Carbonell 1, 03801 Alcoy, Spain; jorarag1@epsa.upv.es (J.A.); jaugoca@epsa.upv.es (J.G.-C.); \\ dagarga4@epsa.upv.es (D.G.-G.) \\ 2 Research Institute of Food Engineering for Development (IIAD), Universitat Politècnica de València (UPV), \\ Camino de Vera s/n, 46022 Valencia, Spain \\ * Correspondence: sanrole@epsa.upv.es (S.R.-L.); storresginer@upv.es (S.T.-G.)
}

Citation: Rojas-Lema, S.; Arevalo, J.; Gomez-Caturla, J.; Garcia-Garcia, D.; Torres-Giner, S. Peroxide-Induced Synthesis of Maleic

Anhydride-Grafted Poly(butylene succinate) and Its Compatibilizing Effect on Poly(butylene succinate)/Pistachio Shell Flour Composites. Molecules 2021, 26, 5927. https://doi.org/10.3390/

molecules26195927

Academic Editor: Andrea Maio

Received: 2 August 2021

Accepted: 24 September 2021

Published: 30 September 2021

Publisher's Note: MDPI stays neutral with regard to jurisdictional claims in published maps and institutional affiliations.

Copyright: (c) 2021 by the authors. Licensee MDPI, Basel, Switzerland. This article is an open access article distributed under the terms and conditions of the Creative Commons Attribution (CC BY) license (https:/ / creativecommons.org/licenses/by/ $4.0 /)$.

\begin{abstract}
Framing the Circular Bioeconomy, the use of reactive compatibilizers was applied in order to increase the interfacial adhesion and, hence, the physical properties and applications of green composites based on biopolymers and food waste derived lignocellulosic fillers. In this study, poly(butylene succinate) grafted with maleic anhydride (PBS-g-MAH) was successfully synthetized by a reactive melt-mixing process using poly(butylene succinate) (PBS) and maleic anhydride (MAH) that was induced with dicumyl peroxide (DCP) as a radical initiator and based on the formation of macroradicals derived from the hydrogen abstraction of the biopolymer backbone. Then, PBS$g$-MAH was used as reactive compatibilizer for PBS filled with different contents of pistachio shell flour (PSF) during melt extrusion. As confirmed by Fourier transform infrared (FTIR), PBS- $g$-MAH acted as a bridge between the two composite phases since it was readily soluble in PBS and could successfully form new esters by reaction of its multiple MAH groups with the hydroxyl $(-\mathrm{OH})$ groups present in cellulose or lignin of PSF and the end ones in PBS. The resultant compatibilized green composites were, thereafter, shaped by injection molding into 4-mm thick pieces with a wood-like color. Results showed significant increases in the mechanical and thermomechanical rigidity and hardness, meanwhile variations on the thermal stability were negligible. The enhancement observed was related to the good dispersion and the improved filler-matrix interfacial interactions achieved by PBS- $g$-MAH and also to the PSF nucleating effect that increased the PBS's crystallinity. Furthermore, water uptake of the pieces progressively increased as a function of the filler content, whereas the disintegration in controlled compost soil was limited due to their large thickness.
\end{abstract}

Keywords: biopolymers; green composites; reactive compatibilization; food waste valorization; Circular Bioeconomy

\section{Introduction}

The rising concern toward environmental issues has stimulated research efforts in the perspective of reducing plastic waste given the fact that, in recent decades, the disposal and non-biodegradability of petroleum derived plastics have caused serious water and land pollution issues. In this context, fully or partially bio-based and biodegradable polymers currently represent the most promising options to replace petrochemical polymers. Some of the biopolymer matrices commonly used are biopolyesters, which mainly include polyhydroxyalkanoates (PHAs) and polylactides (PLAs) as well as aliphatic polyesters that are fully or partially obtained from petroleum but are biodegradable, such as poly $(\varepsilon-$ caprolactone) (PCL), poly(butylene succinate) (PBS), poly(butylene succinate-co-butylene adipate) (PBSA), polybutylene(adipate-co-terephthalate) (PBAT), etc. [1]. Among them, PBS 
is a semicrystalline polyester that can naturally degrade in industrial composting facilities and, under certain conditions, in natural environmental conditions due to the action of some bacteria and fungi [2]. PBS is currently produced at the industrial level by condensation polymerization, that is, polycondensation of petroleum derived 1,4-butanediol and succinic acid. However, both the diacid and diol monomers are underdevelopment to be obtained by the bacterial fermentation route from renewable resources [3]. In general terms, PBS presents good processability and balanced mechanical and thermal properties, closely comparable to some polyolefins [4,5]. In particular, it shows tensile and impact strengths similar to those of polypropylene (PP), whereas its glass transition temperature $\left(\mathrm{T}_{\mathrm{g}}\right)$ and melting temperature $\left(\mathrm{T}_{\mathrm{m}}\right)$ are approximately -32 and $115^{\circ} \mathrm{C}$, respectively, resulting in a thermal profile similar than low-density polyethylene (LDPE) [6]. Furthermore, this biopolyester has a wide melt-processing window, which makes it suitable for extrusion, film blowing, injection molding, fiber spinning, or thermoforming, finding potential applications as packaging films, office supplies, clothing, bags for compost, vegetation nets, mulching films $[7,8]$ and also in biomedical applications $[9,10]$. Nevertheless, PBS is still currently considered an expensive biopolymer, with prices in the 3-6 USD $/ \mathrm{kg}$ range, which is considered to be the main limitation for applications of products fully based on this biopolyester [11].

In this regard, the use cost-effective lignocellulosic fillers could facilitate the market penetration of PBS into the plastics industry in the form of green composites. Thus, the most interesting options are related to the valorization of food or agricultural residues since these raw materials are virtually free and can further improve biodegradability, contributing to the development of the so-called Circular Bioeconomy [12]. As a result, a wide range of agricultural and food waste derived fillers have been recently incorporated into biopolymers in the form of particles or fibers, for example, almond shell [13], coconut fibers [13], orange peel [14], hazelnut shell [15], or coffee husk [16]. In the frame of the Circular Bioeconomy, significant efforts have been particularly dedicated to promote nutshells as lignocellulosic fillers for green composites [17]. In this context, "pistachio" (Pistacia vera L.), a genus that belongs to the Anacardiaceae, is a nut cultivated and available mostly in The United States, Middle East, and some Mediterranean countries [18,19]. In recent years, the annual production of pistachio has increased, especially in Turkey and Iran, reaching a global production of 638,000 $t$ [20]. The pistachio fruit can be classified as a semidry drupe and it is characterized by a high nutritional value, unique flavor, and a bright green color under a purplish skin [21]. However, the seed (kernel) is encased by a thin soft and clear brown coat (testa) enclosed by a creamy lignified shell (endocarp) that is surrounded by a green to yellow-red colored fleshy hull (mesocarp and epicarp), which are not edible and constitute approximately $50 \mathrm{wt} . \%$ of the pistachio nut [22]. Both the hulls and hard shells are currently considered waste from the pistachio industry and, therefore, become a great source of residue or by-product of low economic value. Besides, in the nut trade, it must be considered that pistachio has the advantage that is unique because of shell splitting naturally before harvesting, offering an economical and sustainable advantage compared to almonds or walnuts where their kernels require to be separated from their shells by mechanical cracking [23].

The current major applications of pistachio shell are related to animal feeding and general uses as biomass [24,25], being more recently explored as a source energy [26]. However, interestingly, pistachio shell particles present high hardness since it is mainly composed by cellulose ( 31 wt.\%), hemicellulose ( 42 wt.\%), lignin $(\sim 21 \mathrm{wt} . \%)$, crude protein $(\sim 1 \mathrm{wt} . \%)$, and ashes ( 1 wt.\%) [27], so these can be ground to produce the socalled pistachio shell flour (PSF) that can be used to prepare polymer composites with higher mechanical strength and hardness. For instance, Gürü et al. [28] investigated the possibility of using PSF particles with urea-formaldehyde in composites of particleboard with improved hardness and fire retardant properties. In other study, powder of pistachio shell was mixed with a polyester resin (Polipol 3401-TAB) in order to obtain a polymer composite [29], showing that low filler content of 5 and $10 \mathrm{wt} \%$ allows to achieve a 
better dispersion of the particles and higher mechanical properties. Later, in the research performed by Najafabadi et al. [30], high-density polyethylene (HDPE) was filled with PSF and nanoclays (Cloisite 20A) to improve the mechanical resistance of the polyolefin. More recently, Karaağaç [31] reported the addition of pistachio shell powder as filler in a rubber matrix composed of natural rubber (SIR 20) and styrene-butadiene (CAROM 1502), improving the abrasion resistance, thermal stability, and tensile and aging properties. Nevertheless, this residue has been barely used as raw material in combination with biopolymers to yield green composites.

Unfortunately, the incorporation of lignocellulosic fillers into polymers habitually leads to several issues due to the polar hydroxyl $(-\mathrm{OH})$ groups present on the surface of cellulose having difficulty in forming a well-bonded interface with the non-polar polymer/biopolymer matrix since the hydrogen bonds tend to prevent the wetting of the filler surfaces. This low compatibility between both composite components then affects the filler-matrix interfacial adhesion, which can result in poor filler dispersion and large particle agglomeration, both being detrimental for the mechanical performance of the polymer composites. Furthermore, the presence of the hydrophilic fillers frequently promotes undesirable water uptake phenomena that can cause dimensional changes and ageing in the polymer composites [32]. As a result, different strategies have been used to enhance interfacial adhesion in polymer composites, improving their final properties [33]. Among them, filler surface modification with silane coupling agents [34-36], chemical treatments such as alkenyl succinic anhydride (ASA) or sodium hydroxide (alkaline treatment) [37,38], and plasma treatment [39], have been explored. Furthermore, promising results have been recently achieved by means of the addition of reactive compatibilizers during the extrusion or compounding process, the so-called reactive extrusion [40,41], which is also more cost-effective and easier to scale up. Among the different compatibilizers, the use of graft copolymers containing reactive groups, such as maleic anhydride (MAH) or glycidyl methacrylate (GMA), represents an effective way to improve the interfacial interaction between the polymer and filler and immiscible biopolymer blends [42]. For instance, based on these reactive compatibilizers, a feasible and robust strategy has been recently developed to prepare stable co-continuous blends of PBAT and PLA [43,44].

The use of the same polymer or a highly soluble one as the MAH-grafted matrix makes these agents very compatible with the polymer matrix, whereas the reactive groups can interact with the $-\mathrm{OH}$ groups present on the lignocellulosic filler surface, forming covalent bonds during manufacturing by melt mixing at high temperature. Using this approach, Tserki et al. [45] prepared and, thereafter, incorporated poly(butylene succinate-co-butylene adipate) grafted with maleic anhydride (PBSA-g-MAH) at $5 \mathrm{wt} . \%$ into green composites of PBSA with spruce and olive husk flours at $30 \mathrm{wt} . \%$. Results demonstrated that an increase in the mechanical strength in the green composite $\sim 33 \%$ to $56 \%$ was observed. More specifically, for spruce flour composites, the tensile strength increased from 18.5 to $26.5 \mathrm{MPa}$, reaching values in the range of unfilled PBSA. In another study, Kennouche et al. [46] showed that a high compatibilization was achieved in composites of PHBV/PBS/halloysite nanotubes (HNTs) by poly(3-hydroxybutyrate-co-3-hydroxyvalerate) grafted with maleic anhydride (PHBV-g-MAH). Authors reported an improved dispersion of PBS nodules in the immiscible biopolymer blend with a preferential location of HNTs, owing to the diffusion and emulsifying effect of the PHBV-g-MAH chains. More recently, Muthuraj [47] described composites of PBS/PBAT with miscanthus fibers at $50 \mathrm{wt} . \%$ successfully compatibilized by previously prepared MAH-grafted blends of PBS/PBAT. In particular, tensile strength was increased by approximately $69 \%$ when compared to the uncompatibilized composite.

In the present study, green composites of PBS/PSF at different weight ratios, that is, 5, 10, 20, and $30 \mathrm{wt} . \%$ of filler, were prepared for the first time. In order to enhance the compatibility between PBS and PSF, poly(butylene succinate) grafted with maleic anhydride (PBS-g-MAH) was previously synthesized by a melt-grafting process induced by the presence of an organic peroxide as a radical initiator and, thereafter, added as reactive compatibilizer during melt extrusion at a constant $1 / 6(w t / w t)$ ratio in relation to 
the filler content in the green composite. The resultant compounded pellets were finally shaped into pieces by injection molding and characterized to evaluate the performance of the newly developed green composites.

\section{Results}

\subsection{Morphology of PSF}

Particle morphology, that is, shape, size, and aspect ratio, plays an important role in the reinforcement of polymer composites. Figure 1 shows the morphology of the PSF particles observed by FESEM and their respective length and diameter histograms. One can observe in Figure 1a that the lignocellulosic particles displayed a rod-like morphology, although some platelets and ellipsoidal-like particles were also formed. A similar sheet-like structure was also observed by Bordbar and Mortazavimanesh [42]. The particles also showed a rough surface, which can be attributed to the grinding process performed on hard shells due to their high lignin composition. The particle surfaces also displayed high porosity, as it can be inferred from Figure 1b, showing a FESEM micrograph of the lignocellulosic particles taken at higher magnification. This morphology could be beneficial to interactions with the biopolymer matrix by acting as anchoring points. In this regard, da Silva et al. [48] reported a similar microstructure for the pistachio shell, indicating that both their surface and cross-section show a dense surface with few cracks. This observation is also in agreement with Yang and Lua [49], who showed that the surface of pistachio shell was quite dense without any pores except for some occasional cracks. Regarding the dimensions of the micronized particles, Figure 1c,d gather the histograms in terms of their length and diameter values, respectively. The particles presented an average value of length of $85.8 \pm 47.2 \mu \mathrm{m}$, whereas the average diameter was $16.1 \pm 8.8 \mu \mathrm{m}$, resulting in aspect ratio or length/diameter (L/D) of approximately 5 . In both cases, the particle dimensions were defined by a classical monomodal distribution with a long tale for the fraction of larger particles. Therefore, this particle morphology is based on a relatively low size, which can offer a positive effect on the overall properties of the polymer composite. In this regard, Kadhim et al. [50] proposed that small lignocellulosic particles, of approximately $53 \mu \mathrm{m}$, promoted higher mechanical performance in comparison with particles larger than $100 \mu \mathrm{m}$ in poly(methyl methacrylate) (PMMA) composites.

\subsection{Optical Properies of PBS/PSF Composites}

Figure 2 shows the resultant injection-molded pieces of the PBS and PBS/PSF composites at different filler loadings. This visual appearance is essential in the role that an end product plays in consumers and applications. One can observe that the unfilled PBS sample showed a "cream" color with no transparency. Then, the pieces developed a light brown color when the micronized powder of PSF was added to PBS, which was progressively intensified as a function of the filler content. This color variation can be mainly ascribed to the intrinsic yellow-to-brown color of PSF. However, the strong color variations, particularly at the highest filler contents, can also be influenced by the local high temperature increases that could occur during melt mixing of these formulations due to their higher specific mechanical energy. 

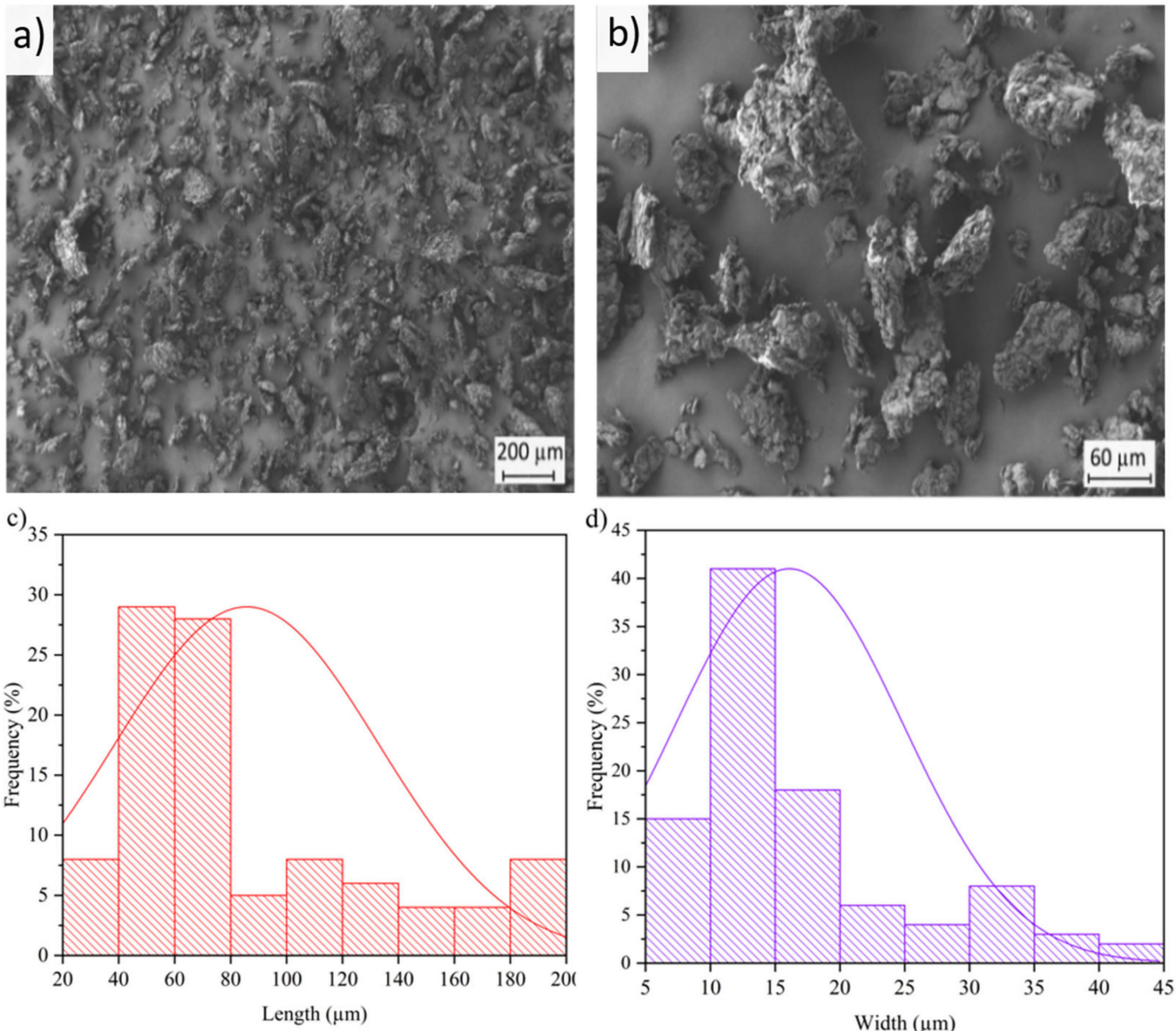

Figure 1. (a) Field emission scanning electron microscopy (FESEM) images of micronized pistachio shell flour (PSF) taken with a magnification of $50 \times$ and a scale marker of $200 \mu \mathrm{m}$; (b) FESEM image of PSF taken with a magnification of $200 \times$ and a scale marker of $60 \mu \mathrm{m}$; (c) histogram of the PSF particle length; (d) histogram of the PSF particle width.

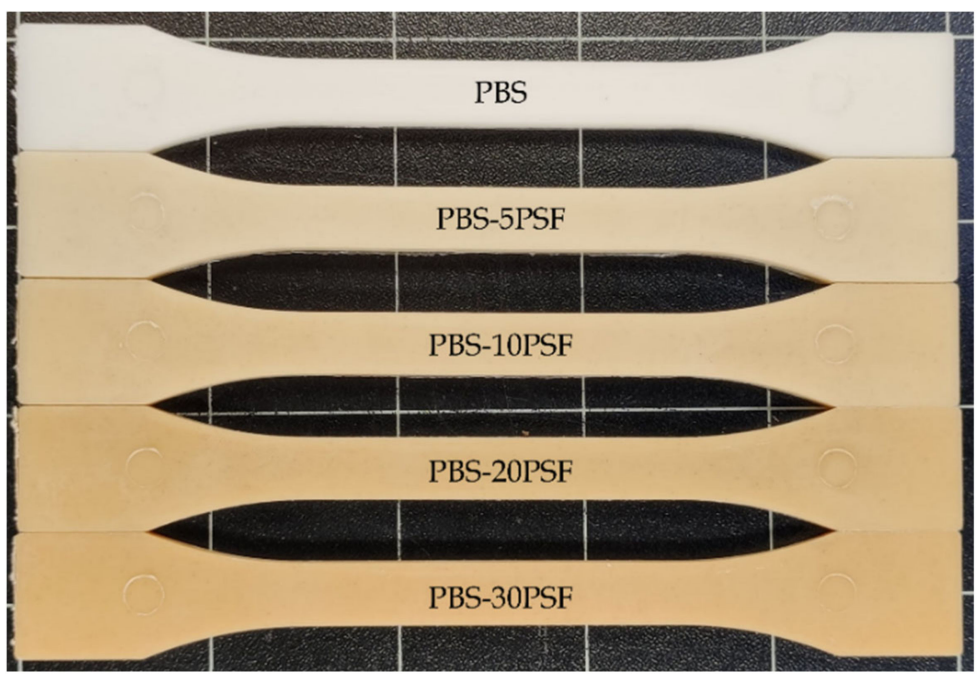

Figure 2. Visual appearance of the injection-molded pieces of poly(butylene succinate) (PBS)/pistachio shell flour (PSF) compatibilized with poly(butylene succinate) grafted with maleic anhydride (PBS-g-MAH). 
Table 1 shows the results of the colorimetric measurements in terms of the $\mathrm{L}^{*} \mathrm{a}^{*} \mathrm{~b}^{*}$ color coordinates and the color difference, that is, $\Delta E_{a b}^{*}$, between the PBS piece and the green composite pieces. One can observe that PBS exhibited a white-to-yellow tonality with values of $L^{*}=83.8$ and values of $a^{*}$ and $b^{*}$ of -1.8 (green) and 1.1 (yellow), respectively. The incorporation of $5 \mathrm{wt}$ \% PSF resulted in a significant color change with a lower luminosity $\left(\mathrm{L}^{*}=71.8\right)$, which represented a percentage difference of $14.3 \%$, and a brownish tonality with values of $\mathrm{a}^{*}$ and $\mathrm{b}^{*}$ of 1.1 (red) and 15.8 (yellow), respectively. The highest addition of PSF both significantly reduced $\mathrm{L}^{*}$, down to 57.8 , and increased $\mathrm{a}^{*}$ and $\mathrm{b}^{*}$ up to values of 6.8 and 25.1, respectively. Therefore, the total color variation between PBS and the different green composite samples increased significantly with the filler content, and it was higher than 19 in all cases. According to the proposed visual evaluation [51], a color variation of $\Delta E_{a b}^{*}>5$ implied that an observer can easily notice different colors. Furthermore, the green composite pieces showed a similar color tonality than some natural woods, a characteristic key property of wood plastic composites (WPCs). For instance, oak without treatment shows color coordinates of $\mathrm{L}^{*}=64.46, \mathrm{a}^{*}=6.77$, and $\mathrm{b}^{*}=20.17$, while pine treated at $160{ }^{\circ} \mathrm{C}$ presents coordinates of $\mathrm{L}^{*}=64.98, \mathrm{a}^{*}=9.34$, and $\mathrm{b}^{*}=27.14$ [52].

Table 1. Luminance $\left(\mathrm{L}^{*}\right)$, color coordinates $\left(\mathrm{a}^{*} \mathrm{~b}^{*}\right)$, and color difference $\left(\Delta E_{a b}^{*}\right)$ of the injectionmolded pieces of poly(butylene succinate) (PBS)/pistachio shell flour (PSF) compatibilized with poly(butylene succinate) grafted with maleic anhydride (PBS- $g-\mathrm{MAH})$.

\begin{tabular}{ccccc}
\hline Piece & $\mathbf{L}^{*}$ & $\mathbf{a}^{*}$ & $\mathbf{b}^{*}$ & $\Delta \boldsymbol{E}_{\boldsymbol{a b}}^{*}$ \\
\hline PBS & $83.8 \pm 0.1^{\mathrm{a}}$ & $-1.8 \pm 0.1^{\mathrm{a}}$ & $1.1 \pm 0.2^{\mathrm{a}}$ & - \\
PBS-5PSF & $71.8 \pm 0.2^{\mathrm{b}}$ & $1.1 \pm 0.1^{\mathrm{b}}$ & $15.8 \pm 0.2^{\mathrm{b}}$ & $19.0 \pm 0.5^{\mathrm{a}}$ \\
PBS-10PSF & $67.6 \pm 0.1^{\mathrm{c}}$ & $2.8 \pm 0.2^{\mathrm{c}}$ & $20.1 \pm 0.1^{\mathrm{c}}$ & $25.0 \pm 0.5^{\mathrm{b}}$ \\
PBS-20PSF & $61.8 \pm 0.1^{\mathrm{d}}$ & $5.1 \pm 0.2^{\mathrm{d}}$ & $23.0 \pm 0.1^{\mathrm{d}}$ & $31.2^{\mathrm{a}} \pm 0.7^{\mathrm{c}}$ \\
PBS-30PSF & $57.8 \pm 0.2^{\mathrm{e}}$ & $6.8 \pm 0.2^{\mathrm{e}}$ & $25.1 \pm 0.1^{\mathrm{e}}$ & $35.7 \pm 0.6^{\mathrm{d}}$ \\
\hline
\end{tabular}

a-e Different letters in the same column indicate a significant difference among the samples $(p<0.05)$.

\subsection{Mechanical Properties of PBS/PSF Composites}

Table 2 shows the mechanical properties of the PBS/PSF composite pieces obtained from the tensile tests. These results are usually of great interest to evaluate the effect of the lignocellulosic filler on the biopolymer and the performance of the composite pieces for different applications. The tensile test results were expressed in terms of tensile modulus (E), maximum tensile strength $\left(\sigma_{\max }\right)$, and elongation at break $\left(\varepsilon_{\mathrm{b}}\right)$.

Table 2. Mechanical properties of the injection-molded pieces of poly(butylene succinate) (PBS)/pistachio shell flour (PSF) compatibilized with poly(butylene succinate) grafted with maleic anhydride (PBS-g-MAH) in terms of tensile modulus $(\mathrm{E})$, maximum tensile strength $\left(\sigma_{\max }\right)$, elongation at break $\left(\varepsilon_{\mathrm{b}}\right)$, Shore D hardness, and impact strength.

\begin{tabular}{cccccc}
\hline Piece & E (MPa) & $\boldsymbol{\sigma}_{\max }(\mathbf{M P a})$ & $\boldsymbol{\varepsilon}_{\mathbf{b}} \mathbf{( \% )}$ & $\begin{array}{c}\text { Shore D } \\
\text { Hardness }\end{array}$ & $\begin{array}{c}\text { Impact } \\
\text { Strength } \\
\mathbf{( k J / \mathbf { m } ^ { 2 } )}\end{array}$ \\
\hline PBS & $598.8 \pm 13.4^{\mathrm{a}}$ & $27.8 \pm 0.5^{\mathrm{a}}$ & $225.5 \pm 15.2^{\mathrm{a}}$ & $62.9 \pm 0.7^{\mathrm{a}}$ & $11.4 \pm 0.8^{\mathrm{a}}$ \\
PBS-5PSF & $605.6 \pm 15.2^{\mathrm{b}}$ & $23.1 \pm 1.3^{\mathrm{b}}$ & $42.9 \pm 3.5^{\mathrm{b}}$ & $63.6 \pm 0.6^{\mathrm{a}}$ & $6.8^{\mathrm{b}} \pm 0.4^{\mathrm{b}}$ \\
PBS-10PSF & $655.5 \pm 18.7^{\mathrm{c}}$ & $20.1 \pm 0.8^{\mathrm{c}}$ & $27.7 \pm 1.7^{\mathrm{c}}$ & $67.8 \pm 0.4^{\mathrm{b}}$ & $5.6 \pm 0.2^{\mathrm{c}}$ \\
PBS-20PSF & $852.2 \pm 28.7^{\mathrm{d}}$ & $17.0 \pm 0.5^{\mathrm{d}}$ & $15.9 \pm 0.7^{\mathrm{d}}$ & $68.8 \pm 0.4^{\mathrm{b}}$ & $3.3 \pm 0.3^{\mathrm{d}}$ \\
PBS-30PSF & $1039.6 \pm 32.5^{\mathrm{e}}$ & $16.0 \pm 1.0^{\mathrm{d}}$ & $9.7 \pm 1.1^{\mathrm{e}}$ & $69.5 \pm 0.5^{\mathrm{c}}$ & $2.9 \pm 0.3^{\mathrm{e}}$ \\
\hline
\end{tabular}

a-e Different letters in the same column indicate a significant difference among the samples $(p<0.05)$.

As a reference point, the properties of the unfilled PBS pieces were analyzed, showing a ductile behavior with $\mathrm{E}$ and $\sigma_{\max }$ values of 598.8 and $27.8 \mathrm{MPa}$, respectively, being the $\varepsilon_{\mathrm{b}}$ value $225.5 \%$. These values are similar to those reported earlier for injection-molded PBS pieces [53], whereas the differences can be ascribed to the molecular weight $\left(\mathrm{M}_{\mathrm{W}}\right)$ and 
crystallinity of the PBS sample. In this regard, Jin et al. [54] showed values of E, tensile strength at yield $\left(\sigma_{\mathrm{y}}\right)$, and $\varepsilon_{\mathrm{b}}$ in the ranges of $280-400 \mathrm{MPa}, 24-35 \mathrm{MPa}$, and $250-640 \%$, respectively, with significant variations depending on the biopolymer's $\mathrm{M}_{\mathrm{W}}$. In particular, the mechanical properties increased with the number-average-molecular weight $\left(\mathrm{M}_{\mathrm{n}}\right)$ of PBS up to $4.1 \times 10^{4} \mathrm{~g} / \mathrm{mol}$, which is similar to the grade used herein, and then decreased with further increasing of $\mathrm{M}_{\mathrm{n}}$. Authors concluded indicating that the best mechanical performance is neither attained for the sample with the highest crystallinity nor for the sample with the highest $\mathrm{M}_{\mathrm{W}}$. One can further observe that the incorporation of PSF increased the E value of the PBS pieces; however, it also resulted in a material with a lower deformation capacity so that the ductile properties of the injection-molded pieces were reduced. In this way, E values of 655.5 and 1039.6 MPa were obtained for the 10PSF and 30PSF pieces, which represents percentage improvements of approximately $9.5 \%$ and $79.6 \%$, respectively, compared to the unfilled PBS piece. However, the effect of PSF on the tensile strength also followed a decreasing trend as a function of the amount of lignocellulosic filler. This variation resulted in $\sigma_{\max }$ values of 17.0 MPa for the 20PSF piece and 16.0 MPa for the 30PSF piece, which means percentage reductions of approximately $38.8 \%$ and $42.2 \%$, respectively. In this regard, it can be considered that the presence of lignocellulosic particles inside the biopolymer matrix acted as a stress concentration and resulted in a lower tensile strength $[50,55]$. Furthermore, the ductility of the pieces was significantly reduced with the PSF content. In the case of the PBS-5PSF, the $\varepsilon_{b}$ value decreased to $42.9 \%$, being approximately 5 times lower than the neat PBS piece. The incorporation of higher amounts of filler further reduced the ductility of the material, but the percentage differences were smaller. For instance, the $\varepsilon_{b}$ value for the PBS-30PSF piece, with 30 wt.\% PSF, reached a value of $9.7 \%$. This embrittlement phenomenon is commonly observed in polymer composites due to the reduction of the movement capacity of the polymer chains by the filler presence and it is particularly critical in the plastic deformation zone, which is drastically reduced [56,57]. The mechanical results reported herein agrees with previous works based on polymer composites filled with pistachio shells. For instance, the work of Kadhim et al. [50] reported that powder of pistachio shell could successfully reinforce PMMA, increasing E from nearly $1 \mathrm{GPa}$ to up to $1.35 \mathrm{GPa}$, whereas $\sigma_{\mathrm{y}}$ and $\varepsilon_{\mathrm{b}}$ decreased from $66 \mathrm{MPa}$ and $5 \%$ to approximately $46 \mathrm{MPa}$ and $1.8 \%$.

Table 2 also shows the results of the Shore D hardness tests. In the case of the unfilled PBS pieces, it showed a hardness value of 62.9. Similar to the E values, the incorporation of PSF to PBS yielded a progressive increase in the hardness of the pieces, which is related to the reduction of the movement of the biopolymer chains [58]. In particular, hardness increased from 63.6, for the PBS-5PSF piece, to 69.5, for that of PBS-30PSF. This Shore $\mathrm{D}$ hardness value is relatively close to, for instance, that of PLA, that is, $\sim 79$, which is considered to be a hard biopolymer material [51]. Finally, results of the Charpy impact test showed a significant reduction in the energy absorption capacity when the micronized lignocellulosic particles were introduced. For instance, whereas the neat PBS piece yielded an impact energy absorption of $11.4 \mathrm{~kJ} / \mathrm{m}^{2}$, the addition of $5 \mathrm{wt} . \%$ PSF resulted in a value of $6.8 \mathrm{~kJ} / \mathrm{m}^{2}$ while the use of $30 \mathrm{wt}$. $\%$ PSF resulted in a value of $2.9 \mathrm{~kJ} / \mathrm{m}^{2}$, which respectively represents percentage reductions of approximately $40.4 \%$ and $74.6 \%$. Impact strength is highly related to the deformation capacity of the material, and those materials with a higher deformation ability show a higher energy absorption in Charpy impact test. In comparison with a previous work in which PBS was filled with $30 \mathrm{wt}$ \% of almond shell flour (ASF), the incorporation of the lignocellulosic particles also decreased impact strength from 16.5 to $1.8 \mathrm{~kJ} / \mathrm{m}^{2}$; however, the use of maleinized linseed oil (MLO) as compatibilizer increased toughness in the green composite to $3.8 \mathrm{~kJ} / \mathrm{m}^{2}$ [53]. 


\subsection{Morphology of PBS/PSF Composites}

In Figure 3, field emission scanning electron microscopy (FESEM) micrographs with the surface fractures of the green composite pieces after the Charpy impact tests can be observed. It can be seen that the morphology of the surface fracture changed from a rough surface, as seen in Figure 3a in the case of the unfilled PBS piece, to a smoother fracture surface with the presence of microcracks in the green composite pieces shown in Figure 3b-e. The latter morphology, with a lower roughness, can be ascribed to the embrittlement of the PBS matrix due to the presence of the lignocellulosic fillers [59]. It should also be underlined the absence of gap surrounding the PSF surface in contact with PBS since the lignocellulosic fillers were completely embedded in the biopolymer matrix, suggesting that PBS-g-MAH successfully compatibilized the two components of the green composite. Similar morphological observations have been previously reported for PBS/ASF compatibilized by MLO, who indicated that a good compatibilization is achieved when the size of these gaps are reduced or even removed [60]. Similar findings were also reported by Phua et al. [61], who similarly proposed PBS-g-MAH for improving the interaction of PBS in nanocomposites prepared with organically modified montmorillonite (OMMT).

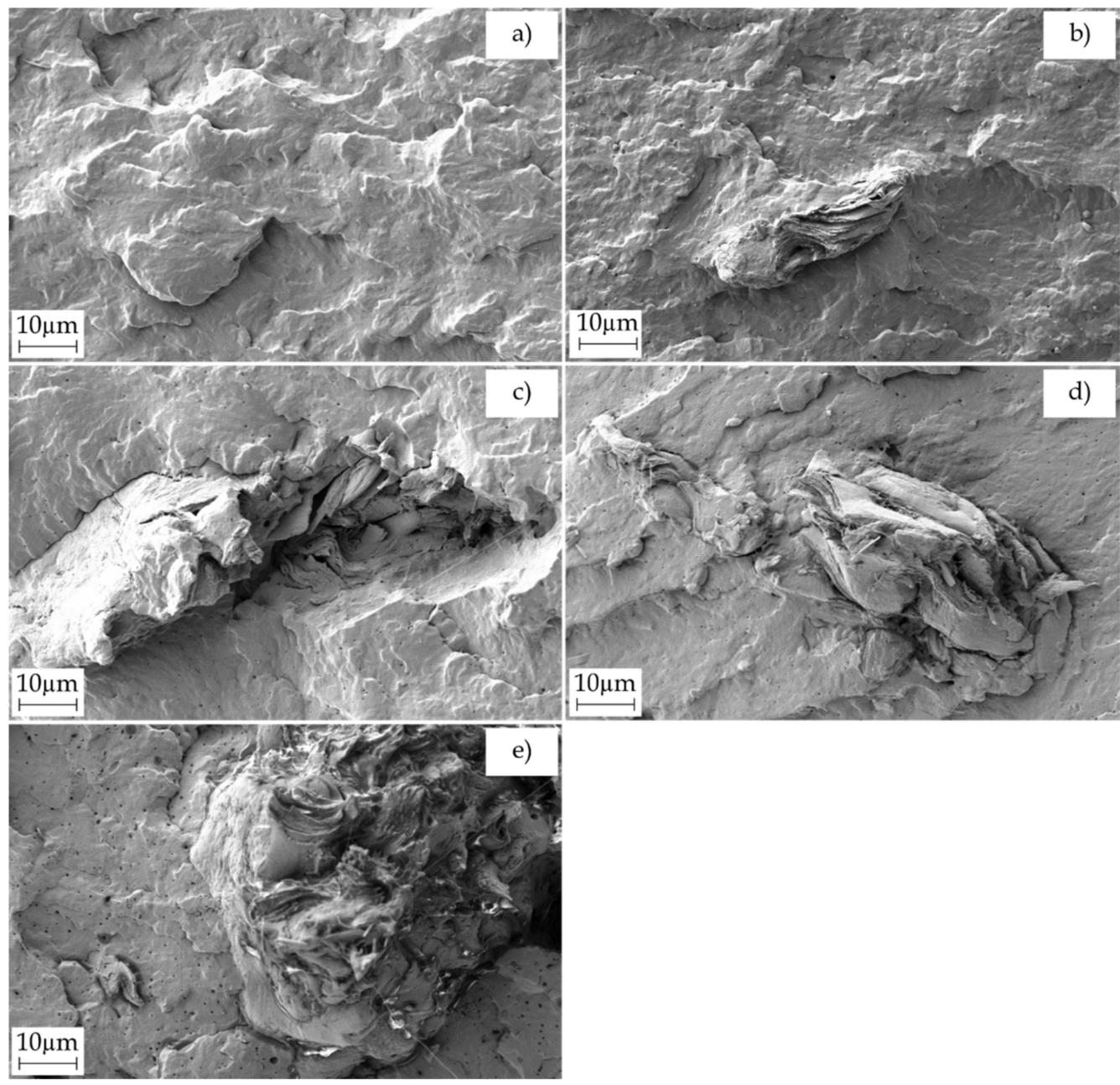

Figure 3. Field emission scanning electron microscopy (FESEM) images of the fracture surfaces of the injection-molded pieces of poly(butylene succinate) (PBS)/pistachio shell flour (PSF) compatibilized with poly(butylene succinate) grafted with maleic anhydride (PBS- $g$-MAH): (a) PBS, (b) PBS-5PSF, (c) PBS-10PSF, (d) PBS-20PSF, and (e) PBS-30PSF. Images were taken at $1000 \times$ with scale markers of $10 \mu \mathrm{m}$. 


\subsection{Spectroscopic Properties of PBS/PSF Composites}

Figure 4 shows the attenuated total reflection-Fourier transform infrared (ATR-FTIR) spectra of the PSF powder, the PBS- $g$-MAH dough, and the injection-molded pieces of neat PBS and its green composites with PSF and PBS- $g$-MAH. It can be seen in Figure $4 a$ that the FTIR spectrum of PSF was mainly characterized by the presence of three strong peaks. It can be observed the first broad and intense band at $\sim 1035 \mathrm{~cm}^{-1}$ wavelength, which can be correlated with $\mathrm{C}-\mathrm{O}$ stretching vibrations in alcohols and phenols of lignocellulose, and it belongs to the polyglykosidic moieties (polyol) [48]. Then, the second strong peak arose at $2910 \mathrm{~cm}^{-1}$, and it corresponds to $v(\mathrm{C}-\mathrm{H})$ vibrations in methyl $\left(-\mathrm{CH}_{3}\right)$ and methylene $\left(-\mathrm{CH}_{2}-\right)$ groups of cellulose and lignin [62]. This band has been indicated to be contrary to the $\delta(\mathrm{C}-\mathrm{H})$ vibrational bands for $-\mathrm{CH}_{3}$ and $-\mathrm{CH}_{2}$ - groups due to the skeletal $\mathrm{C}-\mathrm{C}$ vibrations in aromatic rings, which were also found for pistachio nut shells and located herein at around 1263 and $1412 \mathrm{~cm}^{-1}$ [49]. The latter bands overlapped with those attributed to $\mathrm{C}-\mathrm{O}-\mathrm{H}$ in-plane bending and $\mathrm{C}-\mathrm{O}$ stretching for carboxyl $(-\mathrm{COOH})$ groups in lignin [48]. Finally, the third and also broad peak seen in the region of $3000-3600 \mathrm{~cm}^{-1}$ is indicative of the large presence of hydroxyl $(-\mathrm{OH})$ groups in pistachio shell [63]. Other minor peaks were seen at $1664 \mathrm{~cm}^{-1}$, which occurs due to $\mathrm{C}=\mathrm{C}$ vibrations in aromatic rings and olefinic $v(C-C)$ absorptions present in lignin, and at $1735 \mathrm{~cm}^{-1}$ due to the $\mathrm{C}=\mathrm{O}$ stretching of the carbonyl $(\mathrm{C}=\mathrm{O})$ group, which is mainly associated with hemicellulose [48]. Therefore, from the FTIR spectrum of PSF, it was confirmed the lignocellulosic nature of the food waste derived filler as well as the presence of several oxygen groups on its chemical structure such as carbonyl groups, ethers, esters, alcohols, and phenol groups.

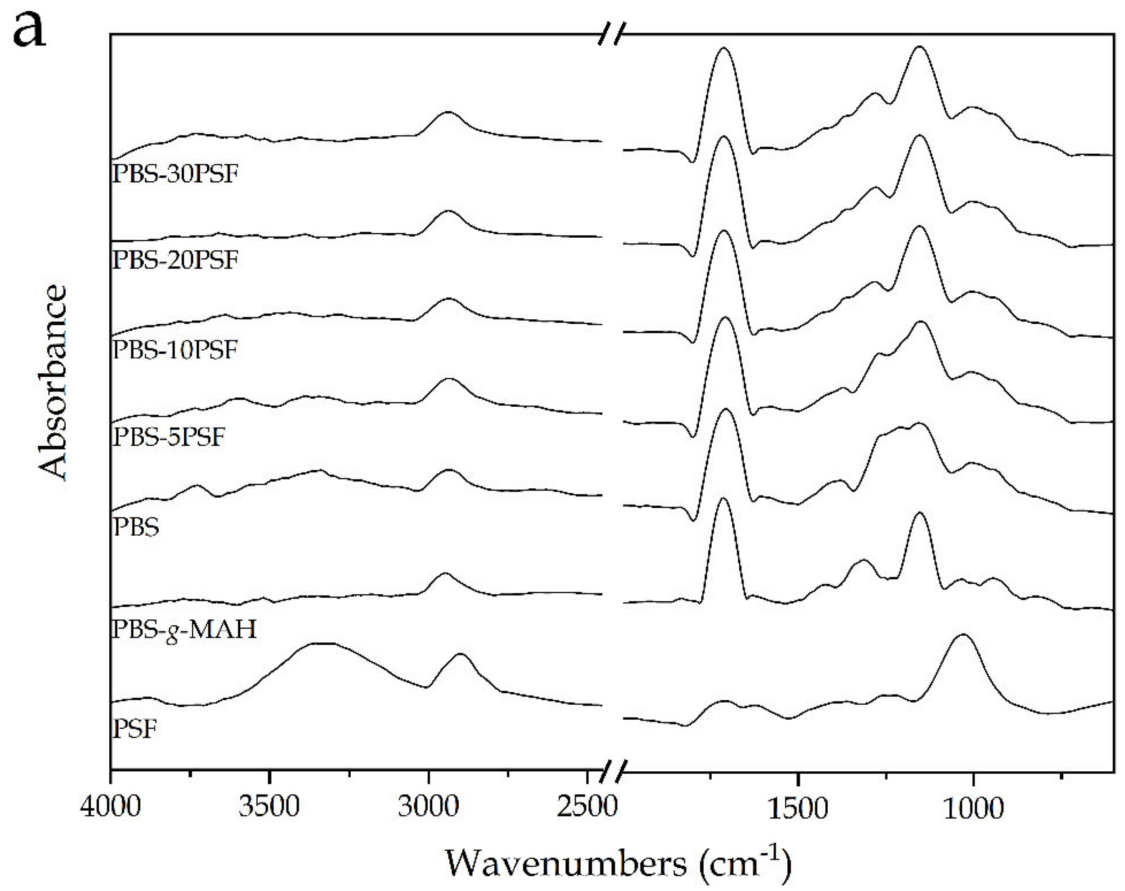

Figure 4. Cont. 


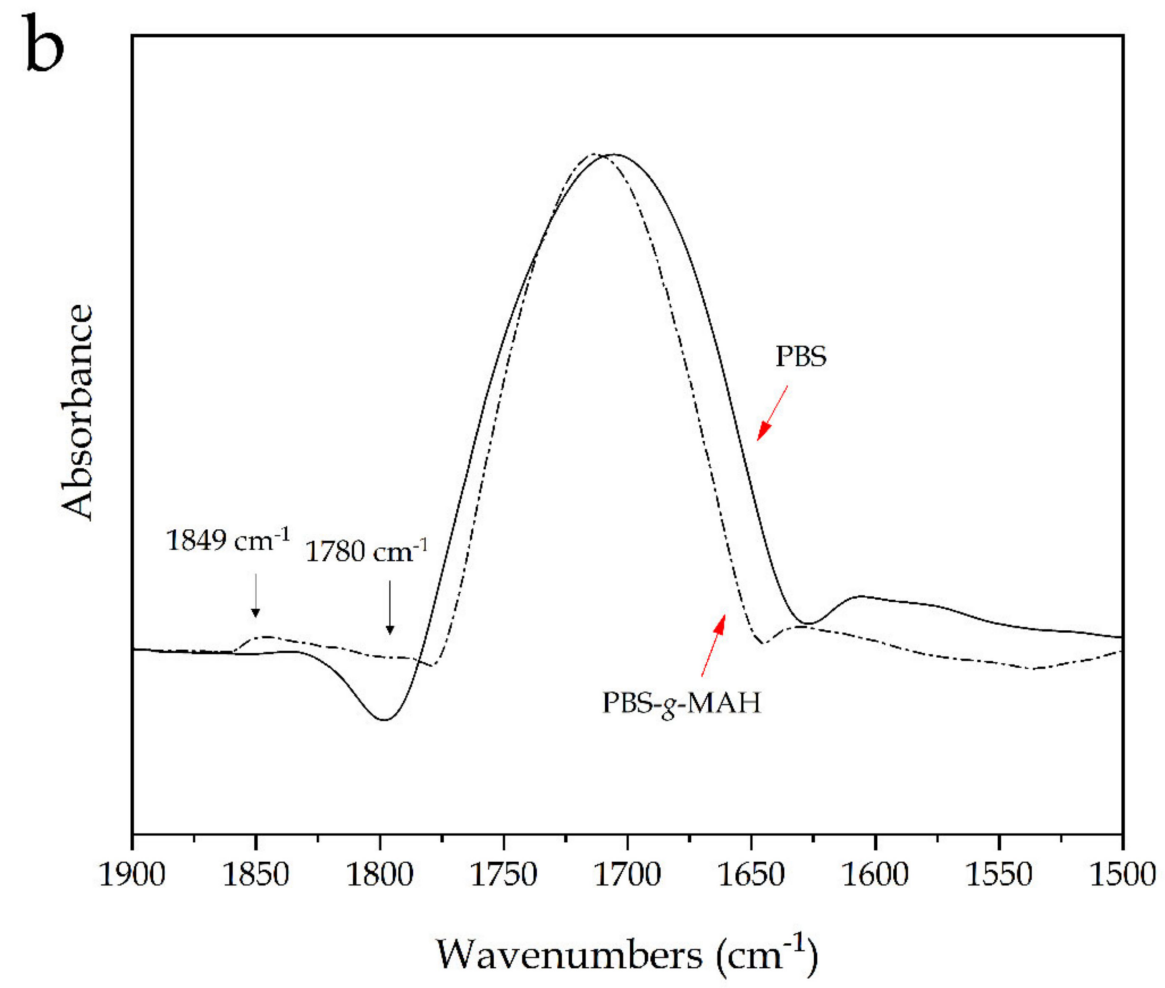

Figure 4. (a) Fourier transform infrared (FTIR) spectra, from bottom to top, of pistachio shell flour (PSF); poly(butylene succinate) grafted with maleic anhydride (PBS-g-MAH), poly(butylene succinate) (PBS), and PBS-5PSF, PBS-10PSF, PBS-20PSF, and PBS-30PSF green composites; (b) Detail of the PBS- $g$-MAH and PBS spectra in the $1900-1500 \mathrm{~cm}^{-1}$ region to show the MAH grafting onto PBS.

The characteristic peaks for PBS, in both the unfilled piece and the green composite pieces, were seen as a strong and sharp band at $\sim 1714 \mathrm{~cm}^{-1}$ wavelength, ascribed to the $\mathrm{C}=\mathrm{O}$ stretching of the ester groups in biopolyester, in addition to multiple peaks in the $1100-1200 \mathrm{~cm}^{-1}$ region mainly corresponding to the $\mathrm{C}-\mathrm{O}$ stretching vibration in the ester groups, and the broad and low-intense peaks at 1330 and $2960 \mathrm{~cm}^{-1}$ due the symmetric and asymmetric stretching vibrations of $-\mathrm{CH}_{2}$ - groups [54]. In relation to the strongest peak, it was reported that the PBS biopolymer can show three absorption bands at 1736, 1720, and $1714 \mathrm{~cm}^{-1}$ wavelengths that are stemmed from $\mathrm{C}=\mathrm{O}$ stretching modes in the mobile amorphous fraction (MAF), rigid amorphous fraction (RAF) (or intermediate phase), and crystalline phase, respectively [64]. Since the crystal lattices should have the strongest confinement effect on $\mathrm{C}=\mathrm{O}$ groups in the lamellar structure of the $\mathrm{PBS}$ crystal, including physical and hydrogen bonding, it was suggested that it is more reasonable to assign the $1714 \mathrm{~cm}^{-1}$ band to the $\mathrm{C}=\mathrm{O}$ in crystal lattices. Therefore, this further confirms the high crystallinity achieved in the PBS samples during injection molding.

The outcome of the MAH grafting onto PBS was also investigated by FTIR. The strongest absorption signal was the one attributed to the $\mathrm{C}=\mathrm{O}$ stretching vibrations of ester groups in PBS, which slightly shifted to $\sim 1720 \mathrm{~cm}^{-1}$ and also narrowed due to crystalline phase disruption and potential loss. By comparison of the PBS-g-MAH and PBS spectra in the 1900-1500 $\mathrm{cm}^{-1}$ region, one can observe in Figure $4 \mathrm{~b}$ that there was a new signal absorption band at $1849 \mathrm{~cm}^{-1}$, which is characteristic for succinic anhydride groups and has been formerly attributed to the symmetric $\mathrm{C}=\mathrm{O}$ stretching bonds of MAH [65]. Furthermore, this was accompanied by a signal level increase at nearly $1780 \mathrm{~cm}^{-1}$, corresponding to their symmetric stretching. Moreover, the peak related to $v(\mathrm{C}-\mathrm{H})$ vibration of PBS was shifted in the PBS- $g$-MAH spectrum from approximately $2965 \mathrm{~cm}^{-1}$ to $2980 \mathrm{~cm}^{-1}$ as a result of the grafting process since it could be affected by the $=\mathrm{CH}_{2}$ vibration of the cyclic MAH that was reported to arise at $3058 \mathrm{~cm}^{-1}$. Although the band changes in the PBS- $g$-MAH were subtle, these have already served to demonstrate the reactive grafting process of MAH 
at the diol unit of PBS [45,61]. All these newly formed bands and band distortions are, thus, representative of the functional groups available in the grafted biopolymer [66-69]. In addition to this, these new peaks did not appear in either the neat PBS spectrum or green composite spectra, suggesting that these groups were removed or consumed during melt grafting.

Finally, it can be observed that all the green composites showed very similar FTIR spectra than neat PBS, with the most noticeable change in the intensity increase of the peak centered at $\sim 1163 \mathrm{~cm}^{-1}$. This band change can be ascribed to the presence of PSF in PBS, with a strong contribution of the $\mathrm{C}-\mathrm{O}$ stretching vibration signals, which was seen at a lower wavelength in the spectrum of the biopolyester. Furthermore, the subsequent broadening of signals in the region of $1300-1400 \mathrm{~cm}^{-1}$, from which multiple peaks with low intensity arise, could be attributed to esters (e.g., $\mathrm{R}-\mathrm{CO}-\mathrm{O}-\mathrm{R}^{\prime}$ ), ethers (e.g., $\mathrm{R}-\mathrm{O}-\mathrm{R}^{\prime}$ ), or phenol groups newly formed due to the grafting reaction of $-\mathrm{OH}$ groups of cellulose and lignin with the MAH groups present in PBS-g-MAH. Moreover, the intensity of the peaks observed in the $1150-1300 \mathrm{~cm}^{-1}$ decreased, which has been ascribed to $-\mathrm{C}-\mathrm{O}-\mathrm{C}-$ groups in the ester linkages of PBS [61], suggesting that the proportional contribution of the original groups in the biopolyester was reduced and also observed at higher wavenumbers due to the potential formation of new ones. Therefore, these peaks variations point to an esterification reaction achieved by the functional MAH groups present in PBS-g-MAH with the $-\mathrm{OH}$ groups of PSF. The scheme of this process is proposed in Figure 5, which illustrates the grafting mechanism of PSF onto PBS by PBS- $g$-MAH. Although PBS- $g$-MAH is readily soluble in PBS, part of their multiple MAH can also react with the $-\mathrm{OH}$ end groups of the biopolyester, both present in acids or alcohols, following the scheme shown in Figure $5 \mathrm{a}$. Moreover, according to the final scheme proposed in Figure $5 b$, other MAH groups can connect with $-\mathrm{OH}$ groups present in the cellulose or lignin of PSF by esterification [70]. Therefore, the here-developed PBS- $g$-MAH acted as a bridge between the PSF filler and the PBS matrix.

\subsection{Thermal Properties of PBS/PSF Composites}

Figure 6 shows the differential scanning calorimetry (DSC) curves for the injectionmolded pieces of PBS and its green composites with PSF in the thermal range from $140{ }^{\circ} \mathrm{C}$ to $20{ }^{\circ} \mathrm{C}$ during cooling (Figure 6a) and from $40{ }^{\circ} \mathrm{C}$ to $175{ }^{\circ} \mathrm{C}$ in the second heating (Figure $6 \mathrm{~b}$ ). In Table 3, the main thermal parameters obtained from the cooling and heating thermograms are summarized, that is, the crystallization temperature $\left(\mathrm{T}_{\mathrm{C}}\right)$, cold crystallization temperature $\left(\mathrm{T}_{\mathrm{CC}}\right)$, melting temperature $\left(\mathrm{T}_{\mathrm{m}}\right)$, and the amount of crystallinity $\left(\mathrm{X}_{\mathrm{C}}\right)$ determined from the melting enthalpy $\left(\Delta \mathrm{H}_{\mathrm{m}}\right)$ of the samples. One can observe that the neat PBS sample first crystallized from the melt at $69.7^{\circ} \mathrm{C}$ and, thereafter, further cold crystallized at $96.6^{\circ} \mathrm{C}$ prior to melting at $113.4^{\circ} \mathrm{C}$. This melting peak value is in the range established for the semi-crystalline PBS homopolymer, showing values from 112 to $116^{\circ} \mathrm{C}$ [7] and also in agreement with those obtained by Kim et al. [71] and Chen et al. [72] who reported values of $112.2^{\circ} \mathrm{C}$ and $114.2^{\circ} \mathrm{C}$, respectively. The formation of PBS crystals during both cooling and also, to a lesser extent, heating, the so-called cold crystallization, has been reported elsewhere, showing $\mathrm{T}_{\mathrm{C}}, \mathrm{T}_{\mathrm{CC}}$, and $\mathrm{T}_{\mathrm{m}}$ values of $80.5,102.5$, and $114.6{ }^{\circ} \mathrm{C}$, respectively [73]. In particular, cold crystallization is a phenomenon mainly associated with high-M $\mathrm{M}_{\mathrm{W}}$ PBS due to the lower number of chain ends involved and, subsequently, reduction in the free volume [74,75]. The incorporation of PSF promoted crystallization from the melt but also slightly delayed cold crystallization, particularly at low filler contents, reaching the highest $\mathrm{T}_{\mathrm{C}}$ and $\mathrm{T}_{\mathrm{CC}}$ values at 77.7 and $102{ }^{\circ} \mathrm{C}$, respectively, for the PBS5PSF sample. This observation suggests that the presence of the lignocellulosic fillers favored crystallization of the PBS molecules. However, the values of $\mathrm{T}_{\mathrm{m}}$ were significantly unaltered whereas the percentage of crystallinity, measured as $\mathrm{X}_{\mathrm{C}}$, increased from $51.8 \%$, for the neat PBS, up to nearly $63 \%$ for the green composites containing 20 and $30 \mathrm{wt} . \%$ PSF. This result indicates that the lignocellulosic fillers acted as heterogeneous nuclei during the formation of crystals and a greater number of molecules could crystallize from 
the melt. The nucleating effect on PBS of other fillers, such as calcium carbonate and distiller grains, has been previously reported by Chen et al. [72] and other authors [76,77]. Similar results were also observed by Liminana et al. [78], who reported an increase in the PBS crystallinity after the incorporation of ASF in different contents from 10 to $50 \mathrm{wt} . \%$. Furthermore, the filler effect on crystal growth could also be maximized by the use of the PBS- $g$-MAH compatibilizer that, as shown above during the morphological analysis, successfully enhanced the interactions between the PBS matrix and the lignocellulosic particles [79]. In this regard, Phua et al. [61] suggested that the improved interaction between PBS and fillers by PBS-g-MAH contributed to the crystallization increase of the biopolyester.

a)

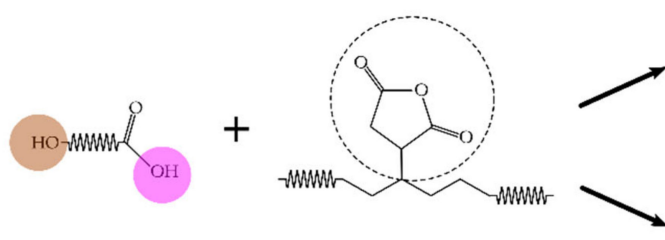

b)<smiles>CC(C)(C)OCCCCOC(=O)CCC(=O)C(C)(C)O</smiles>

Poly(butylene succinate) grafted with maleic anhydride (PBS-g-MAH)

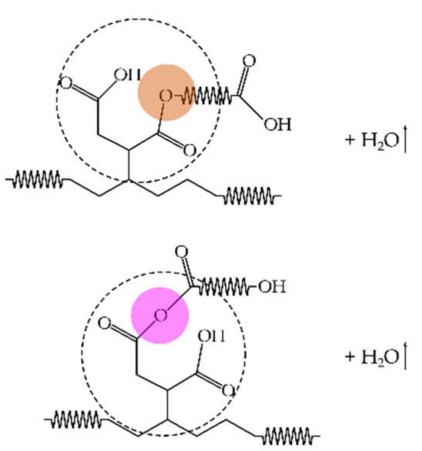

HO-WWWL-PBS-WWWH

$+$

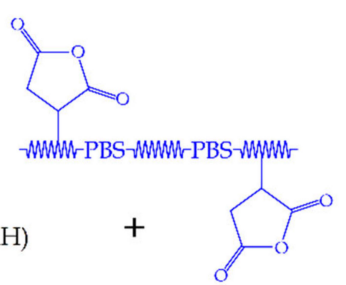

$\ldots \quad \stackrel{\mathrm{OH}}{\mathrm{OH}} \cdots$

Pistachio Shell Flour (PSF)

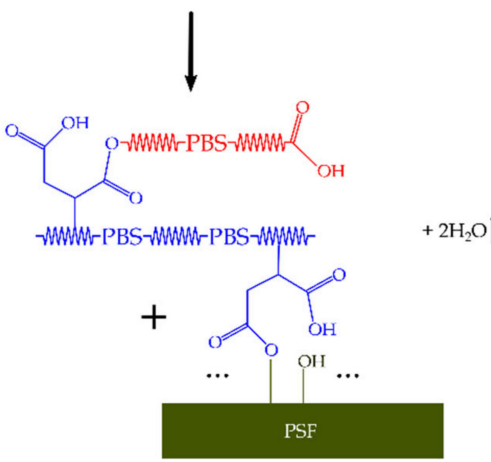

Figure 5. (a) Chemical reaction between the hydroxyl (-OH) end groups of poly(butylene succinate) (PBS) with maleic anhydride (MAH) groups; (b) Melt-grafting process of cellulose or lignin of pistachio shell flour (PSF) onto PBS by esterification reaction of their - OH groups with poly(butylene succinate) grafted with maleic anhydride (PBS- $g$-MAH). 

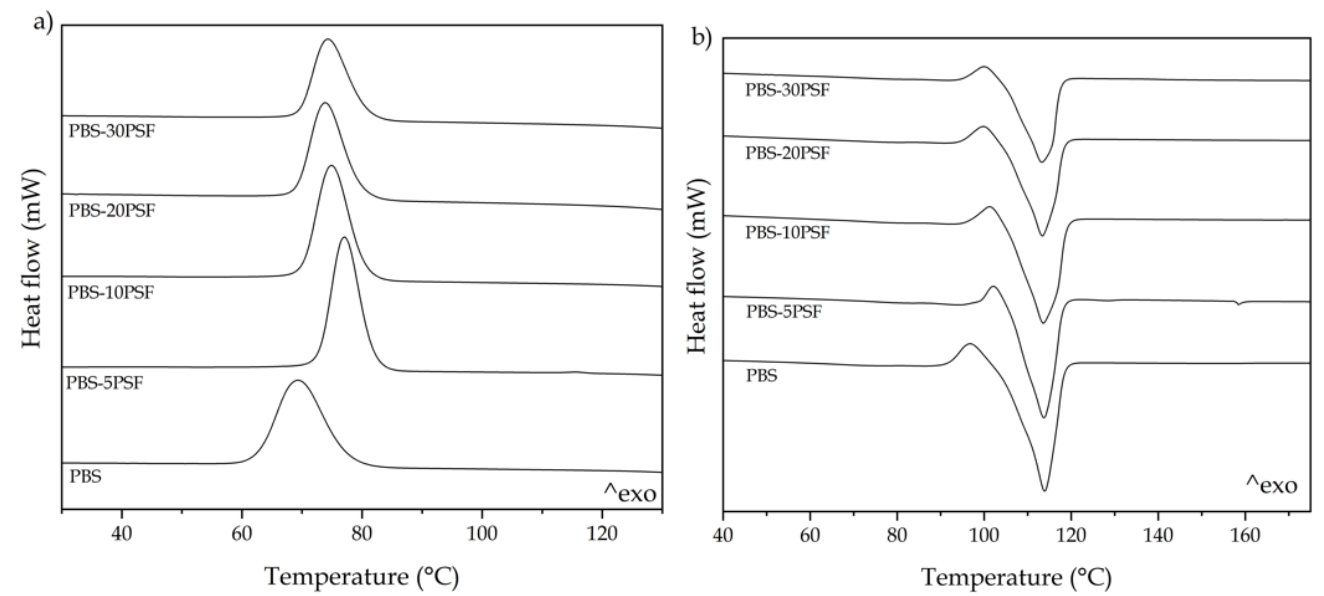

Figure 6. Differential scanning calorimetry (DSC) thermograms taken during cooling (a) and second heating (b) of the injection-molded pieces of poly(butylene succinate) (PBS)/pistachio shell flour (PSF) compatibilized with poly(butylene succinate) grafted with maleic anhydride (PBS- $g-\mathrm{MAH})$.

Table 3. Main thermal parameters of the injection-molded pieces of poly(butylene succinate) (PBS)/pistachio shell flour (PSF) compatibilized with poly(butylene succinate) grafted with maleic anhydride (PBS- $g$-MAH) in terms of crystallization temperature $\left(\mathrm{T}_{\mathrm{c}}\right)$, crystallization enthalpy $\left(\Delta \mathrm{H}_{\mathrm{c}}\right)$, cold crystallization temperature $\left(\mathrm{T}_{\mathrm{cc}}\right)$, cold crystallization enthalpy $\left(\Delta \mathrm{H}_{\mathrm{cc}}\right)$, melting temperature $\left(\mathrm{T}_{\mathrm{m}}\right)$, melting enthalpy $\left(\Delta \mathrm{H}_{\mathrm{m}}\right)$, and crystallinity degree $\left(\mathrm{X}_{\mathrm{c}}\right)$.

\begin{tabular}{|c|c|c|c|c|c|c|c|}
\hline Piece & $\mathrm{T}_{\mathrm{c}}\left({ }^{\circ} \mathrm{C}\right)$ & $\Delta H_{c}(J / g)$ & $\mathrm{T}_{\mathrm{cc}}\left({ }^{\circ} \mathrm{C}\right)$ & $\Delta \mathbf{H}_{\mathrm{cc}}(\mathrm{J} / \mathrm{g})$ & $\mathrm{T}_{\mathrm{m}}\left({ }^{\circ} \mathrm{C}\right)$ & $\Delta H_{m}(J / g)$ & $X_{c}(\%)$ \\
\hline PBS & $69.7 \pm 0.9^{a}$ & $63.8 \pm 0.8^{a}$ & $96.6 \pm 0.4^{a}$ & $5.3 \pm 0.8^{\mathrm{a}}$ & $113.4 \pm 0.8^{a}$ & $62.5 \pm 0.9^{a}$ & $51.8 \pm 1.2^{\mathrm{a}}$ \\
\hline PBS-5PSF & $77.7 \pm 1.1^{b}$ & $65.9 \pm 0.5^{\mathrm{a}}$ & $102.0 \pm 0.7^{b}$ & $3.0 \pm 0.4^{b}$ & $113.3 \pm 0.5^{a}$ & $57.3 \pm 0.7^{b}$ & $52.2 \pm 0.9^{\mathrm{a}}$ \\
\hline PBS-10PSF & $75.5 \pm 0.7^{c}$ & $64.2 \pm 1.0^{\mathrm{a}}$ & $101.4 \pm 0.6^{b}$ & $3.5 \pm 0.6^{c}$ & $113.0 \pm 0.7^{\mathrm{a}}$ & $56.9 \pm 1.1^{b}$ & $54.9 \pm 1.0^{b}$ \\
\hline PBS-20PSF & $74.3 \pm 0.6^{\mathrm{d}}$ & $53.8 \pm 1.2^{b}$ & $99.7 \pm 0.4^{\mathrm{c}}$ & $3.5 \pm 0.8^{c}$ & $112.8 \pm 1.0^{a}$ & $56.6 \pm 0.8^{b}$ & $62.8 \pm 1.2^{c}$ \\
\hline PBS-30PSF & $74.7 \pm 1.1^{\mathrm{d}}$ & $48.2 \pm 0.5^{\mathrm{c}}$ & $99.8 \pm 0.9^{c}$ & $2.5 \pm 0.5^{\mathrm{d}}$ & $112.9 \pm 0.6^{a}$ & $47.5 \pm 1.2^{c}$ & $62.7 \pm 0.7^{c}$ \\
\hline
\end{tabular}

${ }^{\mathrm{a}-\mathrm{d}}$ Different letters in the same column indicate a significant difference among the samples $(p<0.05)$.

Figure 7 shows the thermogravimetric analysis (TGA) and first derivative thermogravimetry (DTG) curves, respectively gathered in Figure 7a,b, for the PBS pieces and their green composite pieces with different contents of PSF. Table 4 presents the main thermal parameters obtained from the thermogravimetric curves, that is, the onset degradation temperature that was considered for the temperature with a loss of $5 \%\left(\mathrm{~T}_{5 \%}\right)$, temperature of maximum degradation $\left(\mathrm{T}_{\mathrm{deg}}\right)$, corresponding to the maximum degradation rate and identified in the corresponding DTG curves, and residual mass at $700{ }^{\circ} \mathrm{C}$. In the case of PSF, like other biomass, three different mass losses were seen during the degradation process, which have been ascribed to drying, devolatilization, and charring [80]. The first mass loss, at $\sim 100{ }^{\circ} \mathrm{C}$, is related to the removal of moisture present in the lignocellulosic material. The second one, in the thermal range from 200 to $400{ }^{\circ} \mathrm{C}$, represents the thermal decomposition of holocellulose, that is, the degradation of hemicellulose $\left(210-325^{\circ} \mathrm{C}\right)$ and cellulose $\left(310-400^{\circ} \mathrm{C}\right)$ [81]. This zone is known as the "active pyrolysis zone" due to its high rate of devolatilization, where occurs the majority of the pyrolysis with a mass loss of $\sim 55 \%$ [40]. Finally, the third zone of degradation started at approximately $310^{\circ} \mathrm{C}$, and it corresponds to the thermal decomposition of the rest of cellulose and lignin, which occurs from $400{ }^{\circ} \mathrm{C}$. This stage is termed "passive pyrolysis" since the mass loss rate is lower compared with the previous stage, and it can be seen as a tailing section in the DGT curve [81]. 

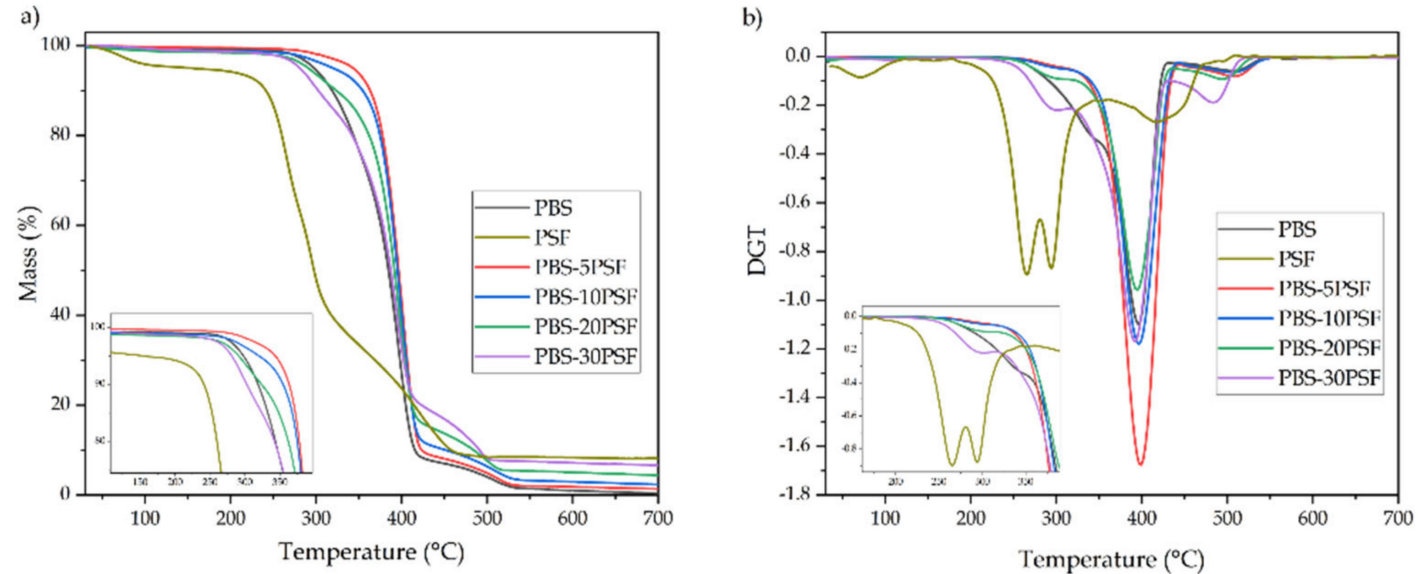

Figure 7. Thermogravimetric analysis (TGA) curves (a) and first derivate thermogravimetric (DTG) curves (b) of the injection-molded pieces of poly(butylene succinate) (PBS)/pistachio shell flour (PSF) compatibilized with poly(butylene succinate) grafted with maleic anhydride (PBS- $g-\mathrm{MAH})$.

Table 4. Main decomposition parameters of the injection-molded pieces of poly(butylene succinate) (PBS)/ pistachio shell flour (PSF) compatibilized with poly(butylene succinate) grafted with maleic anhydride (PBS- $g-\mathrm{MAH})$ in terms of onset degradation temperature at a mass loss of $5 \%\left(\mathrm{~T}_{5} \%\right)$, temperature of maximum degradation $\left(\mathrm{T}_{\mathrm{deg}}\right)$, and residual mass at $700{ }^{\circ} \mathrm{C}$.

\begin{tabular}{cccc}
\hline Piece & $\mathbf{T}_{\mathbf{5} \%}\left({ }^{\circ} \mathbf{C}\right)$ & $\mathbf{T}_{\max }\left({ }^{\circ} \mathbf{C}\right)$ & Residual Mass (\%) \\
\hline PSF & $224.8 \pm 0.9^{\mathrm{a}}$ & $264.8 \pm 0.8^{\mathrm{a}} / 293.7 \pm 1.1^{\mathrm{b}}$ & $8.2 \pm 0.9^{\mathrm{a}}$ \\
PBS & $296.6 \pm 1.0^{\mathrm{b}}$ & $398.3 \pm 0.7^{\mathrm{c}}$ & $0.4 \pm 0.2^{\mathrm{b}}$ \\
PBS-5PSF & $341.9 \pm 0.8^{\mathrm{c}}$ & $401.6 \pm 1.5^{\mathrm{c}}$ & $1.4 \pm 0.5^{\mathrm{c}}$ \\
PBS-10PSF & $318.3 \pm 0.7^{\mathrm{d}}$ & $399.0 \pm 0.7^{\mathrm{c}}$ & $2.3 \pm 0.7^{\mathrm{d}}$ \\
PBS-20PSF & $290.9 \pm 1.2^{\mathrm{e}}$ & $397.4 \pm 0.8^{\mathrm{c}}$ & $4.4 \pm 0.5^{\mathrm{e}}$ \\
PBS-30PSF & $279.6 \pm 1.0^{\mathrm{f}}$ & $394.9 \pm 1.0^{\mathrm{c}}$ & $6.6 \pm 0.8^{\mathrm{f}}$ \\
\hline
\end{tabular}

$\overline{\mathrm{a}-\mathrm{f}}$ Different letters in the same column indicate a significant difference among the samples $(p<0.05)$.

One can observe that PBS was thermally stable up to $\sim 297^{\circ} \mathrm{C}$ and, opposite to other reports [61,82], thermal degradation was seen to occur in two steps. Nevertheless, a twostep thermal decomposition behavior has been widely observed in biopolyesters $[83,84]$. It can be seen that the main and fast mass loss took place from nearly 300 to $405{ }^{\circ} \mathrm{C}$, and it corresponds to the main degradation of the biopolymer backbone, yielding the formation of char with a mass loss of over $90 \%$. The second decomposition step was observed in the $405-525{ }^{\circ} \mathrm{C}$ range, and it is related to the thermo-oxidative degradation of the char produced during the first degradation step, associated with a loss of nearly the totality of the remaining biopolyester. This degradation profile has been reported to occur in thermostable polyesters subjected to air atmosphere [85]. Furthermore, the thermal stability of the green composites, interestingly, revealed that the samples with low filler loadings, that is, filled with 5 and $10 \mathrm{wt} . \%$ PSF, significantly delayed $\mathrm{T}_{5 \%}$. In particular, the PBS-5PSF and PBS-10PSF green composite pieces yielded values of $341.9^{\circ} \mathrm{C}$ and $318.3^{\circ} \mathrm{C}$. Meanwhile, the PBS samples filled with 20 and $30 \mathrm{wt} . \%$ PSF, that is, PBS-20PSF and PBS30PSF, achieved slightly, but still significant, lower onset values of degradation than the neat PBS sample $\left(290.9{ }^{\circ} \mathrm{C}\right.$ and $279.6{ }^{\circ} \mathrm{C}$, respectively). This result suggests that, at low filler contents, the good filler-to-matrix interaction achieved by PBS- $g$-MAH induced a positive effect on thermal degradation due to grafting of the PBS molecules onto the lignocellulosic particles. However, the highest content of fillers slightly impaired the thermal degradation of PBS, which is an effect reported and ascribed to the inherently lower thermal stability of lignocellulose [86]. It is also worth mentioning that, in all cases, due to the presence of the lignocellulosic fillers, the char mass produced during the second degradation step increased. Therefore, in terms of the residual mass, measured at $700{ }^{\circ} \mathrm{C}$, it increased as a 
function of the PSF loading incorporated in the samples, from $0.4 \mathrm{wt} . \%$ for neat PBS, up to a value of $6.6 \mathrm{wt} \%$ in the PBS-30PSF piece. This residual mass corresponds to inorganic residues, such as silica, contained in PSF [72].

\subsection{Thermomechanical Properties of PBS/PSF Composites}

Figure 8 shows the dynamical mechanical thermal analysis (DMTA) curves for the neat PBS pieces and the PBS/PSF composite pieces. Table 5 gathers the most relevant thermomechanical parameters, namely the storage modulus measured at $-45,25$, and $70{ }^{\circ} \mathrm{C}$, which correspond to temperatures below and above each transition region, and also the dynamic damping factor $(\tan \delta)$. In Figure $8 \mathrm{a}$, which shows the evolution of the loss modulus as function of temperature, it can be observed that the PBS piece presented at $-45^{\circ} \mathrm{C}$ the highest value, that is, $1973.3 \mathrm{MPa}$. This high value of storage modulus is due to the amorphous region of the biopolyester at this temperature being in its vitreous state. At higher temperatures, the PBS and its green composites showed two relaxation regions at approximately $-40{ }^{\circ} \mathrm{C}$ and $30^{\circ} \mathrm{C}$, and these low- and high-temperature transitions are respectively related to its $\beta$ - and $\alpha$-relaxations. In particular, the low-temperature transition has been ascribed to the $\beta$-relaxation of the amorphous fractions of PBS, and it is also considered the glass transition of the biopolyester, for which a $\mathrm{T}_{\mathrm{g}}$ value of $-30{ }^{\circ} \mathrm{C}$ has been reported elsewhere [87]. Therefore, in the temperature range from -40 to $25^{\circ} \mathrm{C}$, the storage modulus suffered the most pronounced drop, reaching a value of $440 \mathrm{MPa}$. Thereafter, from nearly $35^{\circ} \mathrm{C}$, a low-intense reduction in the storage modulus was observed, which is indicative of the $\alpha$-relaxation process related to the PBS polymer crystalline fractions [47]. Thus, the storage modulus of the PBS pieces dropped to a value of $214.3 \mathrm{MPa}$ at $70{ }^{\circ} \mathrm{C}$, which is close to the initiation of cold crystallization reported above during DSC analysis. One can further see that the incorporation of PSF reinforced the PBS matrix, and this effect can be easily noticed by the increase in the storage modulus along the whole thermal range tested. Thus, the highest value was attained for the PBS with $30 \mathrm{wt} \%$ of PSF, showing a value of $2161.1 \mathrm{MPa}$ at $-45^{\circ} \mathrm{C}$. This observation agrees with the previous mechanical results, indicating that the lignocellulosic fillers reinforced the PBS matrix and restricted the movement of the biopolymer chains [78]. This result also points out that the use of the PBS- $g$-MAH as compatibilizer facilitates the interaction of PSF with PBS.
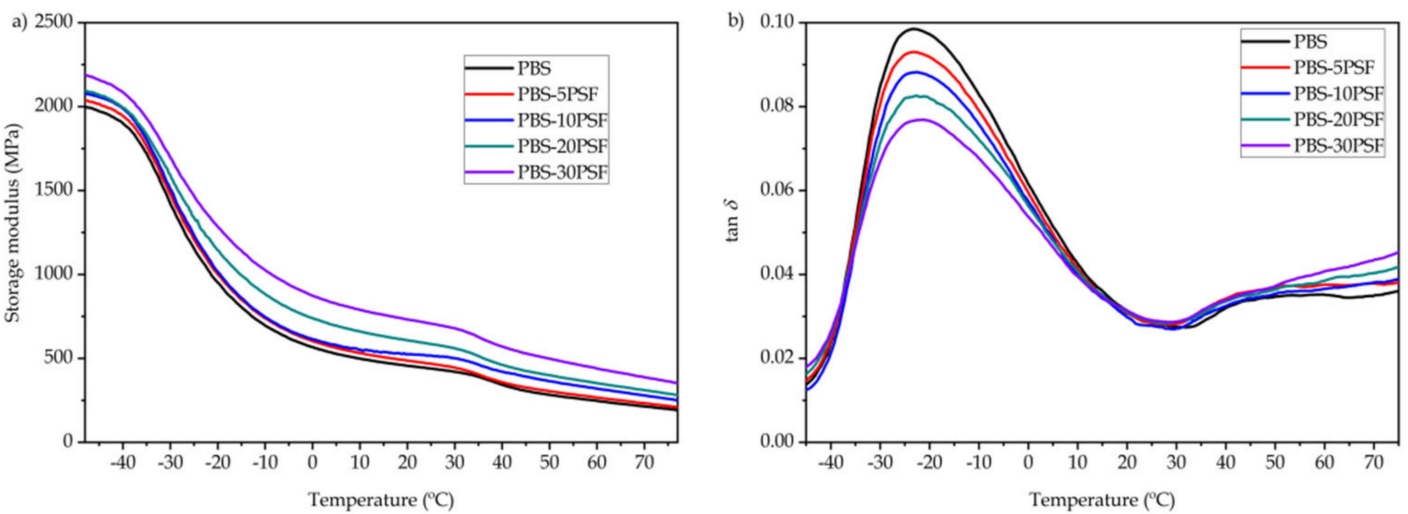

Figure 8. Evolution as function of the temperature of the storage modulus (a) and dynamic damping factor $(\tan \delta)(\mathbf{b})$ of the injection-molded pieces of poly(butylene succinate) (PBS)/ pistachio shell flour (PSF) compatibilized with poly(butylene succinate) grafted with maleic anhydride (PBS- $g-\mathrm{MAH})$. 
Table 5. Thermomechanical properties of the injection-molded pieces of poly(butylene succinate) (PBS) / pistachio shell flour (PSF) compatibilized with poly(butylene succinate) grafted with maleic anhydride (PBS- $g$-MAH) in terms of storage modulus measured at $-45,25$, and $70{ }^{\circ} \mathrm{C}$ and dynamic damping factor $(\tan \delta)$ peak.

\begin{tabular}{ccccc}
\hline \multirow{2}{*}{ Piece } & \multicolumn{3}{c}{ Storage Modulus (MPa) } & \multirow{2}{*}{ tan $\delta$ Peak $\left({ }^{\circ} \mathbf{C}\right)$} \\
\cline { 2 - 4 } & $-\mathbf{4 5}{ }^{\circ} \mathbf{C}$ & $\mathbf{2 5}^{\circ} \mathbf{C}$ & $\mathbf{7 0}^{\circ} \mathbf{C}$ & \\
\hline PBS & $1973.3 \pm 30^{\mathrm{a}}$ & $440 \pm 10^{\mathrm{a}}$ & $214.3 \pm 12^{\mathrm{a}}$ & $-23.3 \pm 0.2^{\mathrm{a}}$ \\
PBS-5PSF & $2016.1 \pm 35^{\mathrm{a}, \mathrm{b}}$ & $468 \pm 21^{\mathrm{a}}$ & $233.1 \pm 20^{\mathrm{a}, \mathrm{b}}$ & $-23.0 \pm 0.1^{\mathrm{b}}$ \\
PBS-10PSF & $2056.5 \pm 37^{\mathrm{a}, \mathrm{b}}$ & $516 \pm 14^{\mathrm{b}}$ & $279.9 \pm 22^{\mathrm{b}, \mathrm{c}}$ & $-22.7^{\mathrm{b}} \pm 0.3^{\mathrm{c}}$ \\
PBS-20PSF & $2072.2 \pm 38^{\mathrm{a}, \mathrm{b}}$ & $585 \pm 12^{\mathrm{c}}$ & $310.3 \pm 17^{\mathrm{c}}$ & $-22.3 \pm 0.4^{\mathrm{d}}$ \\
PBS-30PSF & $2161.1 \pm 34^{\mathrm{b}}$ & $705 \pm 15^{\mathrm{d}}$ & $387.0 \pm 21^{\mathrm{d}}$ & $-21.8 \pm 0.2^{\mathrm{e}}$ \\
\hline $\mathrm{a}-\mathrm{e}$ Different letters in the same column indicate a significant difference among the samples $(p<0.05)$.
\end{tabular}

Figure $8 \mathrm{~b}$ provides the evolution with temperature of $\tan \delta$, also called damping factor, which allows to identify the main relaxations of PBS. As it can also be observed in the table, the neat $\mathrm{PBS}$ showed a $\tan \delta$ peak of $-23.3^{\circ} \mathrm{C}$, which is related to its $\mathrm{T}_{\mathrm{g}}$ and ascribed to the $\beta$-relaxation, whereas it was followed by a low-intense second peak at nearly $45^{\circ} \mathrm{C}$ due to the $\alpha$-relaxation. It can also be observed that the position of the damping factor peaks slightly increased to higher temperatures with the incorporation of PSF, which may indicate that these fillers caused some inhibition of the PBS chain motion [88]. As suggested above, this effect can also be ascribed to the higher interaction achieved due to the reactive grafting with PBS- $g$-MAH. A similar behavior was reported by Liminana et al. [60] with an increase of $T_{g}$ in samples of PBS reinforced with ASF and compatibilized with MLO. Furthermore, it is worth mentioning that all the green composite samples presented lower values of $\tan \delta$ peak than the unfilled PBS sample, decreasing progressively with the PSF content. This reduction is characteristic to materials with lower energy dissipation and reduced toughness, which can be explained by the fact that the biopolymer with amorphous regions was partially replaced with hard lignocellulosic fillers [89].

\subsection{Water Uptake of PBS/PSF Composites}

Figure 9 shows the evolution of water uptake with time in a 14-week immersion period for the PBS pieces and the PBS/PSF composite pieces. In the case of the neat PBS piece, it reached an absorption value of $\sim 0.73 \mathrm{wt} . \%$ after 14 weeks of immersion in water. A similar value was reported previously by Frollini et al. [90], confirming the high hydrophobicity of this biopolyester. Furthermore, it can be observed in the graph that the introduction of the lignocellulosic fillers notably increased the amount of water absorbed in the material during the immersion period. In general, a direct relationship can be observed between the amount of this type of waste derived filler, based on lignocellulose and the total water absorbed in the polymer composite sample [91]. This fact is ascribed to the hydrophilic nature of lignocellulose due to the large amount of free-OH groups on the filler surface [92]. For instance, water uptake increased up to $2.23 \mathrm{wt} . \%$ for the green composite pieces filled with $10 \mathrm{wt} . \%$ PSF, that is, PBS-10PSF, whereas it reached a value of $6.14 \mathrm{wt} . \%$ for a $30 \mathrm{wt} . \%$ filler loading, that is, PBS-30PSF. In this regard, Gairola et al. [93] also reported that PSF shows a great tendency to entrap water, showing a value of water absorption of $2.75 \mathrm{wt} . \%$ after 7 days for a thermosetting epoxy composite with $10 \mathrm{wt}$.\% PSF. Nevertheless, it is worth remarking that all these tests were carried out using injection-molded pieces that were laterally uncoated when fully immersed in water, which may represent more aggressive conditions than those typically found for end-use applications of WPCs. 


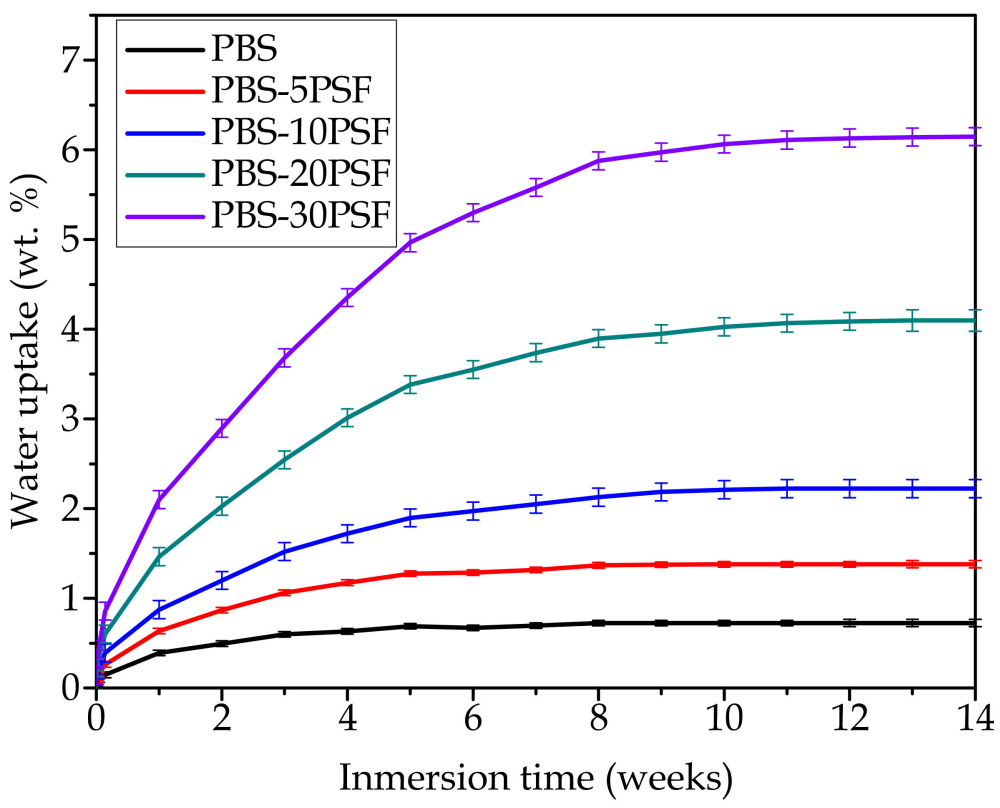

Figure 9. Evolution of the water uptake during a 14-week immersion period of the injection-molded pieces of poly(butylene succinate) (PBS)/ pistachio shell flour (PSF) compatibilized with poly(butylene succinate) grafted with maleic anhydride (PBS- $g$-MAH).

One can also observe that, at the end of the immersion period analyzed, that is, 14 weeks, all samples saturated their water absorption capability. However, the largest mass increases occurred in the first weeks of immersion and, interestingly, this was seen to occur more rapidly in the unfilled PBS sample and the green composites with lower filler loadings. For example, the green composite pieces containing $5 \mathrm{wt} . \%$ PSF saturated after approximately 5 weeks, whereas water uptake was stabilized after 9 weeks of immersion in the green composite pieces filled with 20 and $30 \mathrm{wt} . \%$ of lignocellulosic fillers. In general terms, the use of reactive compatibilizers that show the capacity of anchoring the lignocellulosic fillers to the polymer matrix, which is the case of PBS-g-MAH, can slightly reduce water uptake due to the reduction in the number of freely available $-\mathrm{OH}$ groups [94]. However, better results in terms of hydrophobicity have been achieved by chemical pre-treatments on the filler surface [95]. For instance, it has been reported that lignocellulosic waste flour pre-treated with acetylation or propionylation led to a significant reduction in the percentage of water uptake in PBS green composites, of nearly $50 \%$, whereas the use of compatibilizers yielded lower reductions. This fact was attributed to the substitution of hydrophilic-OH groups of the lignocellulosic material with acetyl and propionyl groups, rendering the lignocellulosic flour surface more hydrophobic [96]. In the case of the compatibilizer addition, the water absorption reduction can be mainly attributed to the formation of covalent bonds between the $\mathrm{MAH}$ groups and the-OH groups at flour surface [97], which are therefore less effective than chemically modified lignocelluloses.

\subsection{Disintegration in Controlled Compost Soil of PBS/PSF Composites}

The disintegration behavior of the PBS and PBS/PSF pieces under controlled composting conditions was analyzed for a period of 112 days, that is, 16 weeks. This timeframe goes beyond the "reasonably short period of time" described in international standards of compostability. In particular, the EN 13432 or ASTM D6400 standards require the plastic articles certified as compostable to disintegrate after 12 weeks or 84 days, and completely biodegrade after 180 days, which means that at least $90 \%$ of the bioplastic material will have been converted to carbon dioxide $\left(\mathrm{CO}_{2}\right)$, water, and biomass. Figure 10 shows results of the disintegration tests in terms of the evolution of the percentage of weight loss (Figure 10a) and the visual aspect of the pieces at each tested time during composting (Figure 10b). It can be observed that, during the first 4 weeks of composting, the mass 
loss was very subtle, and the visual aspect of the pieces remained nearly unaltered. Then, higher rates of disintegration were observed after nearly 35 days of composting, from which all the PBS samples started to loss mass relatively fast whereas the piece surfaces were seen to be eroded. From the week 6 up to approximately 3 months, the pieces showed a linear and very steep degradation progression. At this time, however, the degradation rate was noticeably reduced, and the mass loss reached a value of approximately $20 \mathrm{wt} . \%$ at the end of the test. In this regard, it is worth noting that the test was conducted at $58{ }^{\circ} \mathrm{C}$ and $55 \% \mathrm{RH}$, which are certainly favorable conditions in terms of high temperature and humidity for the hydrolytic degradation of PBS. On the base of the here-attained uncompleted disintegration process, other authors $[98,99]$ also found a similar degradation profile for PBS, identifying three phases with different degradation speeds, namely the lag phase with a low rate ( $<5$ days), biodegradation phase where the rate was accelerated (6-66 days), and plateau phase in which disintegration leveled off ( $>67$ days). Authors also concluded that the shape and format of the PBS articles played a major role during disintegration in controlled compost. In particular, whereas PBS powder with an average particle size of $42 \mu \mathrm{m}$ and the resultant $40 \mu \mathrm{m}$ thermo-compressed film sizing $1 \mathrm{~cm} \times 1 \mathrm{~cm}$ showed biodegradation percentages after 90 days of 71.9 and $60.7 \mathrm{wt} . \%$, respectively, the as-received granules of $\sim 3 \mathrm{~mm}$ only disintegrated up to $14.1 \mathrm{wt} . \%$. It was then confirmed that biodegradability of PBS under composting conditions is mainly controlled by the sample's specific surface area. In another study, it was observed that PBS sheet samples of $30 \mathrm{~mm} \times 30 \mathrm{~mm} \times 1 \mathrm{~mm}$ were discolored after 1 month and their surface was completely damaged by the microorganisms of biodegradation after 3 months, but the sheets did not fully disintegrate in 5 months [45] Therefore, the previous finding supports and agrees with the percentages of degradation achieved herein for the injection-molded pieces of PBS with a thickness of $4 \mathrm{~mm}$, which was approximately $13.4 \mathrm{wt} . \%$ for 91 days and $18.3 \mathrm{wt} . \%$ at the end of the test, that is, after 112 days.

One can also observe that the incorporation of PSF together with PBS- $g$-MAH increased the disintegration rate during the second biodegradation phase, that is, from days 35 to 70 . Then, disintegration progressively increased with the filler content, and this effect may be ascribed to the higher tendency of the fillers to entrap water, as described above during the water uptake analysis, which could then transfer water into the composite by means of the capillary effect favoring the biopolymer hydrolysis of the ester groups [100]. Nevertheless, around day 60, it can be observed that this tendency changed, and the disintegration rate of PBS increased faster than in the case of the green composites. These mass loss changes were correlated with the visual images of the pieces at different times of disintegration, where it can be seen that the unfilled PBS fragmented to a higher extend at the end of the assay, although the development of color dark-to-black changes occurred earlier in the case of the green composites. A similar trend was observed by Quiles-Carrillo et al. [14] during the biodegradation process of green composites of PLA with orange peel flour (OPF) compatibilized by MLO, also showing a slightly slower degradation profile in the final weeks for the green composites in comparison to the unfilled biopolyester. The slower degradation rate in the green composites can be mainly ascribed to a latter increase in water diffusion resistance through the composite due to a tortuosity effect of the fillers on the biopolymer matrix during the plateau phase [101]. Furthermore, the use of PBS-g-MAH could reduce the $-\mathrm{OH}$ concentration and, thus, reduce the water activity. Other authors further suggested that the presence of remaining DCP amounts, which was used herein as radical initiator for the synthesis of PBS- $g$-MAH, could also interfere with the biopolymer chain scission, delaying the biodegradability process [102]. Additionally, it has also been indicated that the presence of diverse mineral fillers, such as talk and chalk, which can be present in minor quantities in pistachio shell, together with silica, can also influence the disintegration behavior of PBS [98,99]. In any case, one should conclude that the large thickness of the pieces certainly limited the appropriate disintegration evaluation of PBS under industrial composting conditions so that the actual effect of the lignocellulosic fillers on compostability was difficult to elucidate. 

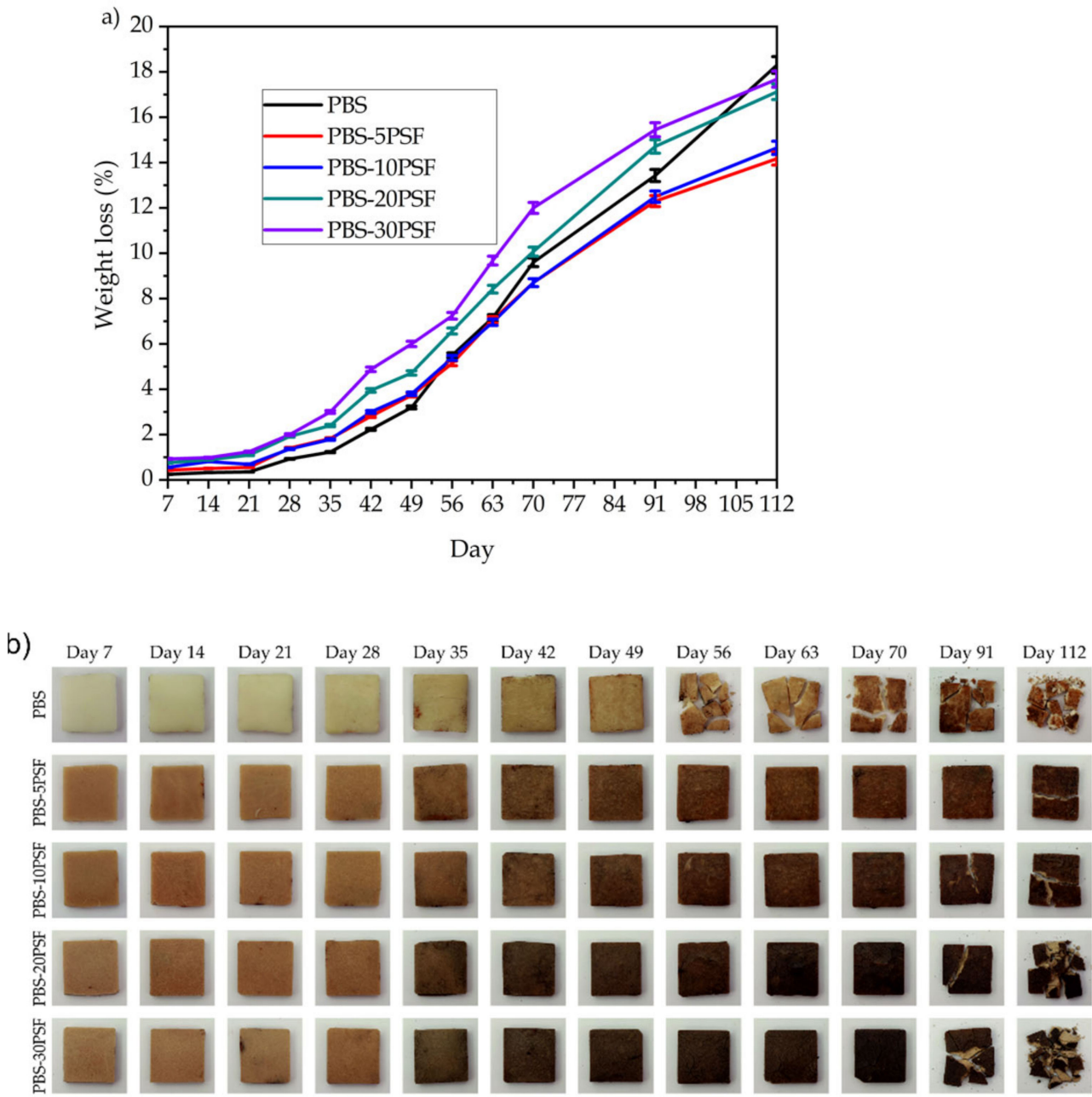

Figure 10. Weight loss as a function of elapsed time during disintegration test in controlled compost soil (a) and visual aspect (b) of the injection-molded pieces of poly(butylene succinate) (PBS)/pistachio shell flour (PSF) compatibilized with poly(butylene succinate) grafted with maleic anhydride (PBS- $g$-MAH).

\section{Discussion}

The present study demonstrates the high potential of pistachio shells, a residue of the agricultural and food industries, to be manufactured in the form of flour for serving as a reinforcing filler in combination with biodegradable polymers to yield green composites in the frame of the Circular Bioeconomy. The incorporation into PBS by melt mixing of low and moderate contents of PSF, below $20 \mathrm{wt} . \%$, and subsequent shaping using injection molding successfully led to the development of material pieces with a wood-like appearance, higher rigidity and hardness, improved crystallinity, and high thermal stability. To improve the inherently low compatibility between this waste derived lignocellulosic, PBS- $g$-MAH was synthetized using DCP as an initiator in a previous step. The grafting methodology achieved herein offers the possibility to produce tailor-made compatibilizers for different green composites since these can be produced with the same biopolymer as the base resin, so that it is fully miscible with the composite matrix, whereas it contains multiple reactive $\mathrm{MAH}$ groups that can chemically interact with the $-\mathrm{OH}$ groups in the cellulose or lignin present on the filler surface by esterification or with those of the biopolyester. As a result of this melt-grafting process, the interfacial filler-matrix adhesion is improved, and the properties of the green composites are enhanced and/or higher filler contents can be loaded. Future works will be dealing with the development of new green composites based on this approach, including the valorization of other agricultural, food, or marine 
wastes, and also a deeper understanding of their degradation mechanisms in different environments.

\section{Materials and Methods}

\subsection{Materials}

PBS Bionolle 1020MD was supplied by Showa Denko Europe (Munich, Germany), which is a liner aliphatic biopolyester characterized by a density of $1.26 \mathrm{~g} / \mathrm{cm}^{3}$ and a melt flow rate (MFR) of $25 \mathrm{~g} / 10 \mathrm{~min}\left(190^{\circ} \mathrm{C}\right.$ and $\left.2.16 \mathrm{~kg}\right)$. It shows a $\mathrm{M}_{\mathrm{n}}$ of $3.7 \times 10^{4} \mathrm{~g} / \mathrm{mol}$ and a dispersity $\left(\bigoplus=\mathrm{M}_{W} / \mathrm{M}_{\mathrm{n}}\right)$ of 1.65 [103]. This PBS grade is mainly designed for injection molding and it is certified as compostable according to the EN-13432 standard.

PSF was obtained from Micronizados Vegetales S.L. (Córdoba, Spain) as a waste of the food industry. The pistachio shells were cleaned and ground into powder form using a jaw crusher. The collected powder was then sieved to obtain a flour composed of particles with a mean size of less than $75 \mu \mathrm{m}$. The raw pistachio shells and the resultant flour in powder form are shown in Figure 11.

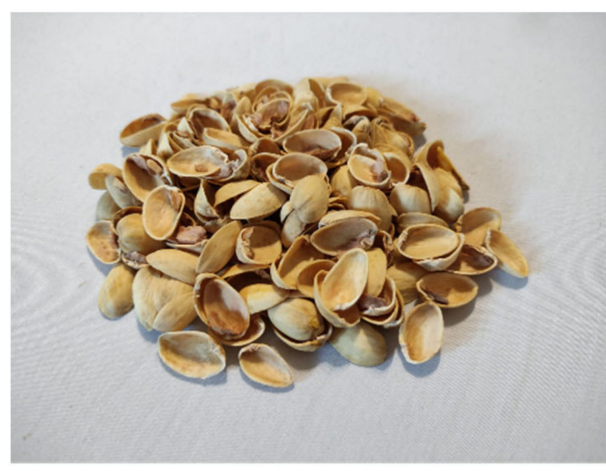

(a)

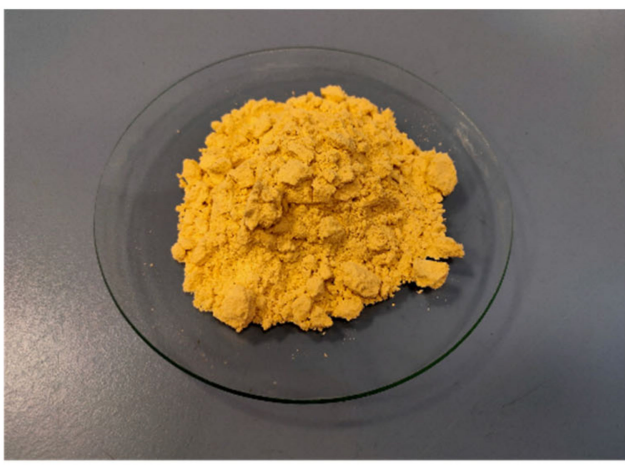

(b)

Figure 11. (a) Pistachio shells; (b) Resultant pistachio shell flour (PSF) after milling and sieving.

MAH and DCP, with purity of $98 \%$, were both purchased at Sigma-Aldrich S.A. (Madrid, Spain) in the form of fine powder.

\subsection{Grafting Procedure}

The grafting reaction was carried out an internal mini-mixer (HAAKETM PolyLabTM QC, Thermo Fisher Scientific, Karlsruhe, Germany) under the conditions established by Phua et al. [61] in the presence of an organic peroxide initiator. Initially, the PBS pellets were physically premixed with the MAH and DCP powders at contents of 10 and 1 parts per hundred resin (phr) of PBS, respectively. Then, the resultant mixture was fed into the melt-mixing device and processed at $135^{\circ} \mathrm{C}$ for $7 \mathrm{~min}$. Thereafter, the resultant dough was purified by refluxing in chloroform (Panreac S.A., Barcelona, Spain) for $4 \mathrm{~h}$, and the hot solution was filtered and precipitated into cold methanol (Sigma-Aldrich S.A.). Finally, in order to remove any unreacted reagents, it was washed with methanol several times, followed by drying at $60^{\circ} \mathrm{C}$ for $24 \mathrm{~h}$ in an air-circulating oven CARBOLITE Eurotherm 2416 CG (Hope Valley, UK).

The degree of grafting $\left(\mathrm{G}_{\mathrm{d}}\right)$ for PBS-g-MAH was determined through titration also following the determination proposed by Phua et al. [61]. Briefly, $1 \mathrm{~g}$ of purified PBS- $g$ MAH was refluxed for $1 \mathrm{~h}$ in $100 \mathrm{~mL}$ of chloroform. Then, $10 \mathrm{~mL}$ of distilled water were added and titrated immediately with $0.025 \mathrm{M}$ potassium hydroxide $(\mathrm{KOH}$, Sigma-Aldrich S.A.) using phenolphthalein (Fisher Scientific SL, Madrid, Spain) as indicator. $G_{d}$ was calculated using Equation (1):

$$
G_{d}(\%)=\left[\frac{N \cdot\left(V_{1}-V_{0}\right) \cdot 98.06}{1000 \cdot W \cdot 2}\right] \times 100
$$


where $N$ is the $\mathrm{KOH}$ concentration [M], $V_{0}$ and $V_{1}$ represent the $\mathrm{KOH}$ volume [mL] for blank solution and for titration of PBS-g-MAH, respectively, and $W$ is the sample weight [g]. A grafting efficiency or $G_{d}$ value of $3.84 \pm 0.27 \%$ was attained.

Figure 12 shows the reaction mechanism to obtain the grafted material, that is, PBS- $g$ $\mathrm{MAH}$. The reaction starts with the peroxide decomposition to form the primary DCP free radicals (I) that abstract the hydrogen atom from PBS backbone to yield PBS macroradicals during the initiation step (II). These biopolymer macroradicals are formed mainly from chain transfer reactions by free radicals that are generated from thermal decomposition of organic initiators [104]. The resultant macroradicals propagated and set off the grafting of MAH onto PBS (III). The reaction continued until the resultant PBS-MAH macroradicals might undergo hydrogen transfer from another biopolymer chains, $\mathrm{MAH}$, or the initiator and formed the so-called PBS-g-MAH (IV). Alternatively, the PBS-MAH macroradicals can react with other radicals in the system, such as MAH, PBS, or primary radicals to form a different structure of PBS- $g$-MAH (V). The formation of side groups and side chains is mainly due to addition of PBS macroradicals to the double bond of MAH molecules and also the combination of PBS macroradicals with those of PBS-MAH. In this regard, it should be considered that other unwanted reaction pathways could occur, for example, the homopolymerization of $\mathrm{MAH}$, that is, $\mathrm{PBS}-(\mathrm{MAH}-)_{\mathrm{n}}$, resulting in a product with higher grafting degree but lesser compatibilization efficiency.

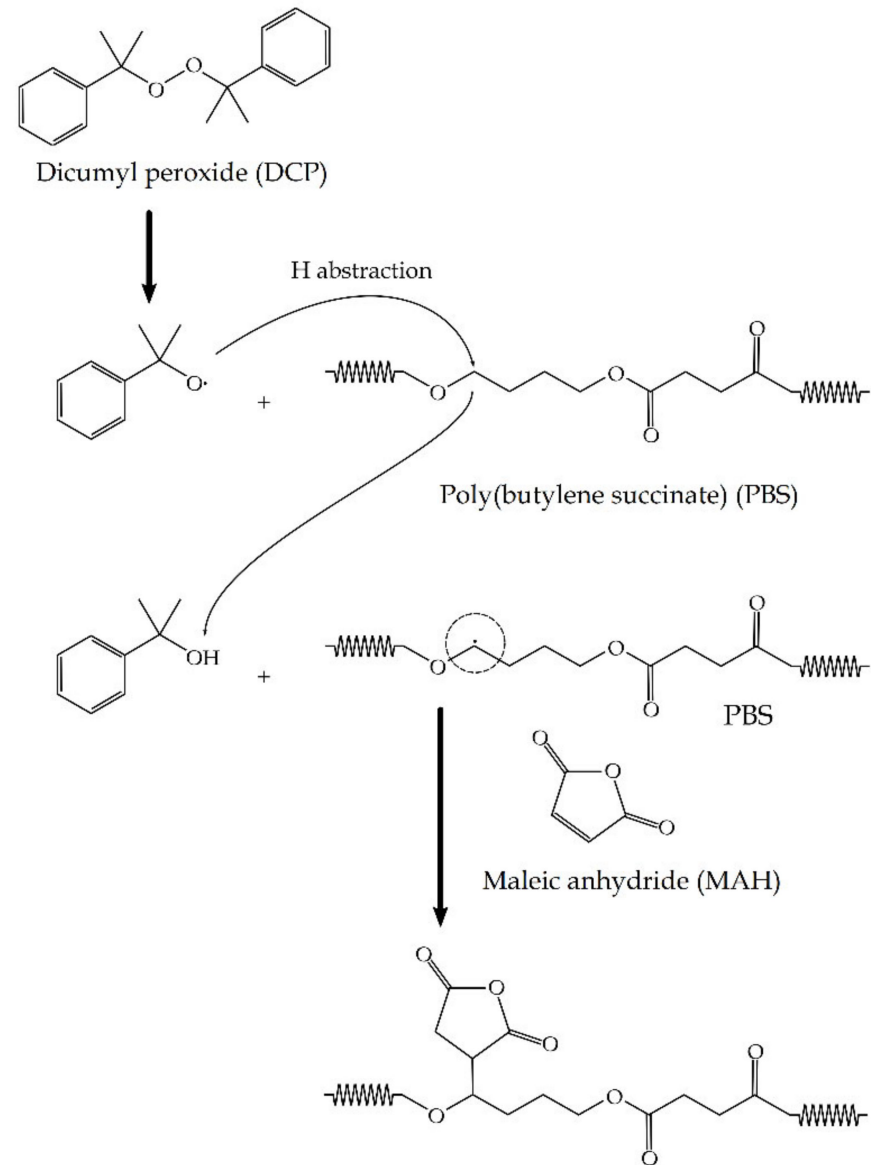

Poly(butylene succinate) grafted with maleic anhydride (PBS- $g$-MAH)

Figure 12. Reaction mechanism to obtain poly(butylene succinate) grafted with maleic anhydride (PBS- $g$-MAH) from poly(butylene succinate) (PBS) and maleic anhydride (MAH) induced by the presence of dicumyl peroxide (DCP). 


\subsection{Preparation of PBS/PSF Composites}

PBS, PBS- $g$-MAH, and PSF were first dried at $50{ }^{\circ} \mathrm{C}$ for $24 \mathrm{~h}$ in an air-circulating oven CARBOLITE Eurotherm 2416 CG to avoid hydrolysis by moisture during the extrusion process. Table 6 shows the compositions used for the compounding process, where PBS- $g$ MAH was added at a constant $1 / 6(w t / w t)$ ratio in relation to the PSF content. The mixtures were weighed and pre-mixed manually in a zip bag that were fed into a co-rotating extruder of Mecánicas Dupra S.L. (Castalla, Spain). This extruder has a diameter of $25 \mathrm{~mm}$ and a $\mathrm{L} / \mathrm{D}$ ratio of 24 . Compounding was carried out at $25 \mathrm{rpm}$ and temperatures of $115-120$ $125-130{ }^{\circ} \mathrm{C}$ (from the hopper to the die), resulting in a residence time of approximately $1 \mathrm{~min}$.

Table 6. Summary of compositions according to the weight content (wt.\%) of poly(butylene succinate) (PBS), pistachio shell flour (PSF), and poly(butylene succinate) grafted with maleic anhydride (PBS-g-MAH).

\begin{tabular}{cccc}
\hline Composition & PBS (wt. $\%$ ) & PSF (wt. $\%$ ) & PBS- $g$-MAH (wt.\%) \\
\hline PBS & 100.00 & 0.00 & 0.00 \\
PBS-5PSF & 94.20 & 5.00 & 0.83 \\
PBS-10PSF & 88.30 & 10.00 & 1.67 \\
PBS-20PSF & 76.60 & 20.00 & 3.30 \\
PBS-30PSF & 65.00 & 30.00 & 5.00 \\
\hline
\end{tabular}

Test specimens were thereafter obtained by injection molding using a Meteor 270/75 from Mateu \& Solé (Barcelona, Spain) machine. The processing conditions consisted of a temperature profile of $120-125-130-135^{\circ} \mathrm{C}$ (from the hopper to the injection nozzle), cavity filling and cooling times of 1 and $10 \mathrm{~s}$, respectively, and a clamping force of $75 \mathrm{t}$. Standard samples with an average thickness of $4 \mathrm{~mm}$ were produced.

\subsection{Characterization of PBS/PSF Composite Pieces \\ 4.4.1. Morphological Characterization}

The morphology of the PSF particles and the fractured samples obtained from the Charpy tests were studied by field emission scanning electron microscopy (FESEM) in a ZEISS ULTRA 55 microscope from Oxford Instruments (Abingdon, UK) using an acceleration voltage of $2 \mathrm{kV}$. Prior to observation, the samples were sputtered with a gold-palladium alloy in an EMITECH sputter coating SC7620 model from Quorum Technologies, Ltd. (East Sussex, UK). The FESEM measurements were carried out using an acceleration voltage of $2 \mathrm{kV}$. Size values were obtained using the ImageJ program in 1.8 version from the National Institutes of Health (Bethesda, MD, USA) using, at least, 20 FESEM images in their original magnification.

\subsubsection{Color Characterization}

Color changes were measured with a Konica CM-3600d Colorflex-DIFF2, from Hunter Associates Laboratory, Inc. (Reston, VA, USA). The CIELAB color space $\left(\mathrm{L}^{*}, \mathrm{a}^{*}, \mathrm{~b}^{*}\right)$ was determined in which $\mathrm{L}^{*}$ refers to lightness of the sample while the coordinates $\mathrm{a}^{*}$ stands for the green $\left(a^{*}<0\right)$ to red $\left(a^{*}>0\right)$ and $b^{*}$ for the blue $\left(b^{*}<0\right)$ to yellow $\left(b^{*}>0\right)$. Equation (2) shows the expression used to obtain the color differences compared with the neat PBS piece.

$$
\Delta E_{a b}^{*}=\sqrt{\left(\Delta \mathrm{L}^{*}\right)^{2}+\left(\Delta \mathrm{a}^{*}\right)^{2}+\left(\Delta \mathrm{b}^{*}\right)^{2}}
$$

Evaluation of color change was assessed following previous criteria [51]: unnoticeable $\left(\Delta E_{a b}^{*}<1\right)$, only an experienced observer can notice the difference $\left(\Delta E_{a b}^{*} \geq 1\right.$ and $\left.<2\right)$, an unexperienced observer notices the difference $\left(\Delta E_{a b}^{*} \geq 2\right.$ and $\left.<3.5\right)$, clear noticeable difference $\left(\Delta E_{a b}^{*} \geq 3.5\right.$ and $\left.<5\right)$, and the observer notices different colors $\left(\Delta E_{a b}^{*} \geq 5\right)$. 


\subsubsection{Mechanical Characterization}

The tensile properties of the PBS/PSF pieces with dimensions of $150 \mathrm{~mm} \times 10 \mathrm{~mm}$ $\times 4 \mathrm{~mm}$ were obtained using the ELIB 50 universal test machine from Ibertest (Madrid, Spain) according to ISO 527-1:2012 with a 5-kN load cell and a testing speed of $5 \mathrm{~mm} / \mathrm{min}$. Hardness was measured according to ISO 868:2003 with a Shore-D scale using a 676-D hardness tester from J. Bot Instruments (Barcelona, Spain) on rectangular samples sizing $80 \mathrm{~mm} \times 10 \mathrm{~mm} \times 4 \mathrm{~mm}$. Finally, impact strength was measured according to ISO 1791:2010 with a 1-J pendulum from Metrotec S.A. (San Sebastian, Spain), using V-notched samples with a radius of $0.25 \mathrm{~mm}$ and sizes of $80 \mathrm{~mm} \times 10 \mathrm{~mm} \times 4 \mathrm{~mm}$. All measurements were carried out at room temperature and, for each of the test, at least 6 measurements were performed.

\subsubsection{Infrared Spectroscopy}

Chemical analysis of the PSF powder, PBS- $g$-MAH, and the pieces of PBS and PBS/PSF composites was performed by ATR-FTIR spectroscopy. For the test, a Bruker S.A Vector 22 (Madrid, Spain) was used, coupled to a PIKE MIRacle ${ }^{\mathrm{TM}}$ single reflection diamond ATR accessory (Madison, WI, USA). Spectra were collected as the average of 10 scans between 4000 and $500 \mathrm{~cm}^{-1}$ with a resolution of $2 \mathrm{~cm}^{-1}$.

\subsubsection{Thermal Analysis}

DSC was carried out in a Mettler-Toledo 821 calorimeter (Schwerzenbach, Switzerland). All the tests were performed with samples with an average weight of 6-7 mg, and the thermal program was divided into three stages: a first heating from 25 to $130{ }^{\circ} \mathrm{C}$, followed by a cooling to $0{ }^{\circ} \mathrm{C}$, and a second heating to $250{ }^{\circ} \mathrm{C}$, all with all heating/cooling rates at $10^{\circ} \mathrm{C} / \mathrm{min}$. Tests were run in nitrogen atmosphere with a flow-rate of $66 \mathrm{~mL} / \mathrm{min}$ using standard sealed aluminum crucibles with a capacity of $40 \mu \mathrm{L}$. The degree of crystallinity $\left(X_{C}\right)$ was measured following Equation (3):

$$
X_{C}=\left[\frac{\Delta H_{m}-\Delta H_{c c}}{\Delta H_{m}^{0} \times(1-w)}\right] \times 100
$$

Where $\Delta H_{m}(\mathrm{~J} / \mathrm{g})$ is the melting enthalpy, $\Delta H_{m}^{0}(\mathrm{~J} / \mathrm{g})$ represents the theoretical enthalpy of a fully crystalline sample of PBS with a value of $110.3 \mathrm{~J} / \mathrm{g}$ [53,105], and the term $1-w$ is the weight fraction of PBS.

Thermal degradation of the green composite pieces was assessed by TGA in a LINSEIS TGA 1000 (Selb, Germany). All samples, with a weight of $15-17 \mathrm{mg}$, were placed in $70 \mu \mathrm{L}$ alumina crucibles, a dynamic heating program from 40 to $700{ }^{\circ} \mathrm{C}$ at a heating rate of $10{ }^{\circ} \mathrm{C} / \mathrm{min}$ in air atmosphere. All thermal tests were performed in triplicate to obtain averaged results.

\subsubsection{Thermomechanical Characterization}

Dynamical mechanical thermal analysis (DMTA) was carried out in a DMA1 dynamic analyzer from Mettler-Toledo (Schwerzenbach, Switzerland), working in single cantilever flexural mode. Rectangular samples sizing $20 \mathrm{~mm} \times 6 \mathrm{~mm} \times 2.7 \mathrm{~mm}$ were subjected to a dynamic temperature sweep from -45 to $75{ }^{\circ} \mathrm{C}$ and a heating rate of $2{ }^{\circ} \mathrm{C} / \mathrm{min}$. The selected frequency was set at $1 \mathrm{~Hz}$, and the maximum deformation was $10 \mu \mathrm{m}$.

\subsubsection{Water Absorption Test}

Injection-molded samples of $4 \mathrm{~mm} \times 10 \mathrm{~mm} \times 80 \mathrm{~mm}$ were immersed in distilled water at room temperature. Samples were first weighted in a balance and then immersed in distilled water. All of them were wrapped within a metal grid to ensure the correct immersion. Thereafter, the weight of all the sample pieces was measured in intervals of different time intervals for up to 14 weeks. For each measurement, prior to annotate 
weight, the surface moisture of the samples was removed with tissue paper. The amount of absorbed water during the process was calculated following Equation (4):

$$
\Delta \mathrm{m}_{\mathrm{t}}(\%)=\frac{\mathrm{W}_{\mathrm{t}}-\mathrm{W}_{0}}{\mathrm{~W}_{0}} \times 100
$$

where $W_{0}$ and $W_{t}$ represent the initial weight before the immersion and the weight of the sample after each immersion time.

\subsubsection{Disintegration Test}

Disintegration of the PBS/PSF composite pieces was evaluated under composting conditions at $58{ }^{\circ} \mathrm{C}$ and $55 \% \mathrm{RH}$ following the recommendations of ISO 20200. Injectionmolded pieces sizing $20 \mathrm{~mm} \times 20 \mathrm{~mm} \times 4 \mathrm{~mm}$ were placed in a carrier bag and buried in a controlled soil compost made of sawdust (40 wt.\%), rabbit-feed (30 wt.\%), ripe compost (10 wt.\%), corn starch (10 wt.\%), saccharose (5 wt.\%), corn seed oil (4 wt.\%), and urea (1 wt.\%). Once a week, each sample was unburied from the composting facility, washed with distilled water, dried, and weighed in an analytical balance. The weight loss during disintegration was calculated using Equation (5):

$$
\text { Weight loss }(\%)=\frac{\mathrm{W}_{0}-\mathrm{W}_{\mathrm{t}}}{\mathrm{W}_{0}} \times 100
$$

where $W_{0}$ is weight of the sample before the immersion and $W_{t}$ is the weight of the sample in each measure. All tests were carried out by triplicate to obtain an average.

Author Contributions: S.R.-L., methodology, formal analysis, investigation, writing-original draft preparation; J.A., methodology, formal analysis, investigation, data analysis; J.G.-C., methodology, formal analysis; D.G.-G., conceptualization, formal analysis, project administration; S.T.-G., conceptualization, writing - review and editing, project administration. All authors have read and agreed to the published version of the manuscript.

Funding: This research was funded by the Ministry of Science and Innovation (MICI) project number MAT2017-84909-C2-2-R.

Institutional Review Board Statement: Not applicable.

Informed Consent Statement: Not applicable.

Data Availability Statement: Not applicable.

Acknowledgments: S.R.-L. is grateful to Generalitat Valenciana (GVA) for her Grisolia GRISOLIAP/2019/132. S.T.-G. acknowledges MICI for his Ramón y Cajal contract (RYC2019-027784-I).

Conflicts of Interest: The authors declare no conflict of interest.

Sample Availability: Samples are available from the authors.

\section{References}

1. Torres-Giner, S.; Figueroa-Lopez, K.J.; Melendez-Rodriguez, B.; Prieto, C.; Pardo-Figuerez, M.; Lagaron, J.M. Emerging Trends in Biopolymers for Food Packaging. In Sustainable Food Packaging Technology; Athanassiou, A., Ed.; Wiley-VCH GmbH: Weinheim, Germany, 2021; pp. 1-33. [CrossRef]

2. Bajpai, P. Biobased Polymers: Properties and Applications in Packaging; Elsevier: Amsterdam, The Netherlands, 2019 ; pp. 1-231. [CrossRef]

3. Babu, R.P.; O'Connor, K.; Seeram, R. Current progress on bio-based polymers and their future trends. Prog. Biomater. 2013, 2, 8. [CrossRef]

4. Signori, F.; Pelagaggi, M.; Bronco, S.; Righetti, M.C. Amorphous/crystal and polymer/filler interphases in biocomposites from poly (butylene succinate). Thermochim. Acta 2012, 543, 74-81. [CrossRef]

5. Bhatia, A.; Gupta, R.K.; Bhattacharya, S.N.; Choi, H. Compatibility of biodegradable poly(lactic acid) (PLA) and poly(butylene succinate) (PBS) blends for packaging application. Korea-Aust. Rheol. J. 2007, 19, 125-131. 
6. Jacquel, N.; Freyermouth, F.; Fenouillot, F.; Rousseau, A.; Pascault, J.P.; Fuertes, P.; Saint-Loup, R. Synthesis and properties of poly(butylene succinate): Efficiency of different transesterification catalysts. J. Polym. Sci. Part A Polym. Chem. 2011, 49, 5301-5312. [CrossRef]

7. Xu, J.; Guo, B.H. Microbial succinic acid, its polymer poly(butylene succinate), and applications. In Plastics from Bacteria; Chen, G.G.-Q., Ed.; Springer: Berlin, Germany, 2010; pp. 347-388. [CrossRef]

8. Siracusa, V.; Lotti, N.; Munari, A.; Dalla Rosa, M. Poly(butylene succinate) and poly(butylene succinate-co-adipate) for food packaging applications: Gas barrier properties after stressed treatments. Polym. Degrad. Stab. 2015, 119, 35-45. [CrossRef]

9. Cheng, H.H.; Xiong, J.; Xie, Z.N.; Zhu, Y.T.; Liu, Y.M.; Wu, Z.Y.; Yu, J.; Guo, Z.X. Thrombin-Loaded Poly (butylene succinate)-Based Electrospun Membranes for Rapid Hemostatic Application. Macromol. Mater. Eng. 2018, 303, 1700395. [CrossRef]

10. Gigli, M.; Fabbri, M.; Lotti, N.; Gamberini, R.; Rimini, B.; Munari, A. Poly(butylene succinate)-based polyesters for biomedical applications: A review. Eur. Polym. J. 2016, 75, 431-460. [CrossRef]

11. Nazrin, A.; Sapuan, S.; Zuhri, M.; Ilyas, R.; Syafiq, R.; Sherwani, S. Nanocellulose reinforced thermoplastic starch (TPS), polylactic acid (PLA), and polybutylene succinate (PBS) for food packaging applications. Front. Chem. 2020, 8. [CrossRef]

12. Liu, R.; Peng, Y.; Cao, J.; Chen, Y.J.C.S. Comparison on properties of lignocellulosic flour/polymer composites by using wood, cellulose, and lignin flours as fillers. Compos. Sci. Technol. 2014, 103, 1-7. [CrossRef]

13. Quiles-Carrillo, L.; Montanes, N.; Sammon, C.; Balart, R.; Torres-Giner, S. Compatibilization of highly sustainable polylactide/almond shell flour composites by reactive extrusion with maleinized linseed oil. Ind. Crop. Prod. 2018, 111, 878-888. [CrossRef]

14. Quiles-Carrillo, L.; Montanes, N.; Lagaron, J.M.; Balart, R.; Torres-Giner, S. On the use of acrylated epoxidized soybean oil as a reactive compatibilizer in injection-molded compostable pieces consisting of polylactide filled with orange peel flour. Polym. Int. 2018, 67, 1341-1351. [CrossRef]

15. Montava-Jordà, S.; Quiles-Carrillo, L.; Richart, N.; Torres-Giner, S.; Montanes, N. Enhanced Interfacial Adhesion of Polylactide/Poly(E-caprolactone)/Walnut Shell Flour Composites by Reactive Extrusion with Maleinized Linseed Oil. Polymers 2019, 11, 758. [CrossRef]

16. Ortiz-Barajas, D.L.; Arévalo-Prada, J.A.; Fenollar, O.; Rueda-Ordóñez, Y.J.; Torres-Giner, S. Torrefaction of Coffee Husk Flour for the Development of Injection-Molded Green Composite Pieces of Polylactide with High Sustainability. Appl. Sci. 2020, 10, 6468. [CrossRef]

17. Sutivisedsak, N.; Cheng, H.N.; Burks, C.S.; Johnson, J.A.; Siegel, J.P.; Civerolo, E.L.; Biswas, A. Use of Nutshells as Fillers in Polymer Composites. J. Polym. Environ. 2012, 20, 305-314. [CrossRef]

18. Tonbul, Y. Pyrolysis of pistachio shell as a biomass. J. Therm. Anal. Calorim. 2008, 91, 641-647. [CrossRef]

19. Kasiri, N.; Fathi, M. Production of cellulose nanocrystals from pistachio shells and their application for stabilizing Pickering emulsions. Int. J. Biol. Macromol. 2018, 106, 1023-1031. [CrossRef]

20. Taghizadeh-Alisaraei, A.; Assar, H.A.; Ghobadian, B.; Motevali, A. Potential of biofuel production from pistachio waste in Iran. Renew. Sustain. Energy Rev. 2017, 72, 510-522. [CrossRef]

21. Ling, B.; Zhang, B.; Li, R.; Wang, S. Nutritional quality, functional properties, bioactivity, and microstructure of defatted pistachio kernel flour. J. Am. Oil Chem. Soc. 2016, 93, 689-699. [CrossRef]

22. Cardullo, N.; Leanza, M.; Muccilli, V.; Tringali, C. Valorization of Agri-Food Waste from Pistachio Hard Shells: Extraction of Polyphenols as Natural Antioxidants. Resources 2021, 10, 45. [CrossRef]

23. Kashaninejad, M.; Tabil, L. Pistachio (Pistacia vera L.). In Postharvest Biology and Technology of Tropical and Subtropical Fruits; Yahia, E.M., Ed.; Elsevier: Cambridge, UK, 2011; pp. 218e-247e. [CrossRef]

24. Apaydin-Varol, E.; Pütün, E.; Pütün, A.E. Slow pyrolysis of pistachio shell. Fuel 2007, 86, 1892-1899. [CrossRef]

25. Okutucu, C.; Duman, G.; Ucar, S.; Yasa, I.; Yanik, J. Production of fungicidal oil and activated carbon from pistachio shell. J. Anal. Appl. Pyrolysis 2011, 91, 140-146. [CrossRef]

26. Açıkalın, K.; Karaca, F.; Bolat, E. Pyrolysis of pistachio shell: Effects of pyrolysis conditions and analysis of products. Fuel 2012, 95, 169-177. [CrossRef]

27. Hesam, F.; Tarzi, B.G.; Honarvar, M.; Jahadi, M. Pistachio (Pistacia vera) shell as a new candidate for enzymatic production of xylooligosaccharides. J. Food Meas. Charact. 2021, 15, 33-45. [CrossRef]

28. Gürü, M.; Şahin, M.; Tekeli, S.; Tokgöz, H. Production of polymer matrix composite particleboard from pistachio shells and improvement of its fire resistance by fly ash. High Temp. Mater. Process. 2009, 28, 191-195. [CrossRef]

29. Alsaadi, M.; Erkliğ, A.; Albu-khaleefah, K. Effect of pistachio shell particle content on the mechanical properties of polymer composite. Arab. J. Sci. Eng. 2018, 43, 4689-4696. [CrossRef]

30. Najafabadi, M.A.; Khorasani, S.N.; Esfahani, J.M. High density polyethylene/pistachio shell flour/nanoclay composites-effect of accelerated weathering conditions on mechanical properties, relative brightness and total colour change. Polym. Polym. Compos. 2017, 25, 299-308. [CrossRef]

31. Karaağaç, B. Use of ground pistachio shell as alternative filler in natural rubber/styrene-butadiene rubber-based rubber compounds. Polym. Compos. 2014, 35, 245-252. [CrossRef]

32. Lascano, D.; Guillen-Pineda, R.; Quiles-Carrillo, L.; Ivorra-Martínez, J.; Balart, R.; Montanes, N.; Boronat, T. Manufacturing and Characterization of Highly Environmentally Friendly Sandwich Composites from Polylactide Cores and Flax-Polylactide Faces. Polymers 2021, 13, 342. [CrossRef] 
33. Agüero, Á.; Garcia-Sanoguera, D.; Lascano, D.; Rojas-Lema, S.; Ivorra-Martinez, J.; Fenollar, O.; Torres-Giner, S. Evaluation of Different Compatibilization Strategies to Improve the Performance of Injection-Molded Green Composite Pieces Made of Polylactide Reinforced with Short Flaxseed Fibers. Polymers 2020, 12, 821. [CrossRef]

34. Carbonell-Verdú, A.; García-García, D.; Jordá, A.; Samper, M.; Balart, R. Development of slate fiber reinforced high density polyethylene composites for injection molding. Compos. Part B Eng. 2015, 69, 460-466. [CrossRef]

35. Quiles-Carrillo, L.; Boronat, T.; Montanes, N.; Balart, R.; Torres-Giner, S. Injection-molded parts of fully bio-based polyamide 1010 strengthened with waste derived slate fibers pretreated with glycidyl- and amino-silane coupling agents. Polym. Test. 2019, 77, 105875. [CrossRef]

36. Gharbi, A.; Hassen, R.B.; Boufi, S. Composite materials from unsaturated polyester resin and olive nuts residue: The effect of silane treatment. Ind. Crop. Prod. 2014, 62, 491-498. [CrossRef]

37. Acha, B.A.; Aranguren, M.I.; Marcovich, N.E.; Reboredo, M.M. Composites from PMMA modified thermosets and chemically treated woodflour. Polym. Eng. Sci. 2003, 43, 999-1010. [CrossRef]

38. Mohammed, M.H.; Dauda, B. Unsaturated polyester resin reinforced with chemically modified natural fibre. IOSR J. Polym. Text. Eng. 2014, 1, 31-38.

39. Yuan, X.; Jayaraman, K.; Bhattacharyya, D. Effects of plasma treatment in enhancing the performance of woodfibre-polypropylene composites. Compos. Part A Appl. Sci. Manuf. 2004, 35, 1363-1374. [CrossRef]

40. Melendez-Rodriguez, B.; Torres-Giner, S.; Aldureid, A.; Cabedo, L.; Lagaron, J.M. Reactive Melt Mixing of Poly(3Hydroxybutyrate)/Rice Husk Flour Composites with Purified Biosustainably Produced Poly(3-Hydroxybutyrate-co-3Hydroxyvalerate). Materials 2019, 12, 2152. [CrossRef]

41. Torres-Giner, S.; Montanes, N.; Boronat, T.; Quiles-Carrillo, L.; Balart, R. Melt grafting of sepiolite nanoclay onto poly(3hydroxybutyrate-co-4-hydroxybutyrate) by reactive extrusion with multi-functional epoxy-based styrene-acrylic oligomer. Eur. Polym. J. 2016, 84, 693-707. [CrossRef]

42. Muthuraj, R.; Misra, M.; Mohanty, A.K. Biodegradable compatibilized polymer blends for packaging applications: A literature review. J. Appl. Polym. Sci. 2018, 135, 45726. [CrossRef]

43. Chen, J.; Rong, C.; Lin, T.; Chen, Y.; Wu, J.; You, J.; Wang, H.; Li, Y. Stable Co-Continuous PLA/PBAT Blends Compatibilized by Interfacial Stereocomplex Crystallites: Toward Full Biodegradable Polymer Blends with Simultaneously Enhanced Mechanical Properties and Crystallization Rates. Macromolecules 2021, 54, 2852-2861. [CrossRef]

44. Wang, H.; Wei, B.; Gu, X.; Lin, T.; Li, Y. Determining the optimal molecular architecture for reactive splicing compatibilization: Toward a better understanding of reactive polymer processing. Polymer 2020, 208, 122948. [CrossRef]

45. Tserki, V.; Matzinos, P.; Panayiotou, C. Novel biodegradable composites based on treated lignocellulosic waste flour as filler. Part II. Development of biodegradable composites using treated and compatibilized waste flour. Compos. Part A Appl. Sci. Manuf. 2006, 37, 1231-1238. [CrossRef]

46. Kennouche, S.; Le Moigne, N.; Kaci, M.; Quantin, J.-C.; Caro-Bretelle, A.-S.; Delaite, C.; Lopez-Cuesta, J.-M. Morphological characterization and thermal properties of compatibilized poly(3-hydroxybutyrate-co-3-hydroxyvalerate) (PHBV)/poly (butylene succinate) (PBS)/halloysite ternary nanocomposites. Eur. Polym. J. 2016, 75, 142-162. [CrossRef]

47. Muthuraj, R.; Misra, M.; Mohanty, A.K. Biocomposite consisting of miscanthus fiber and biodegradable binary blend matrix: Compatibilization and performance evaluation. RSC Adv. 2017, 7, 27538-27548. [CrossRef]

48. da Silva, J.C.G.; Alves, J.L.F.; Galdino, W.V.d.A.; Moreira, R.d.F.P.M.; José, H.J.; de Sena, R.F.; Andersen, S.L.F. Combustion of pistachio shell: Physicochemical characterization and evaluation of kinetic parameters. Environ. Sci. Pollut. Res. 2018, 25, 21420-21429. [CrossRef] [PubMed]

49. Yang, T.; Lua, A.C. Characteristics of activated carbons prepared from pistachio-nut shells by physical activation. J. Colloid Interface Sci. 2003, 267, 408-417. [CrossRef]

50. Kadhim, N.N.; Hamad, Q.A.; Oleiwi, J.K. Tensile and Morphological Properties of PMMA Composite Reinforced by Pistachio Shell Powder Used in Denture Applications. In Proceedings of the 2nd International Conference on Materials Engineering and Science (IConMEAS 2019), Baghdad, Iraq, 25-26 September 2019.

51. Agüero, A.; Morcillo, M.C.; Quiles-Carrillo, L.; Balart, R.; Boronat, T.; Lascano, D.; Torres-Giner, S.; Fenollar, O. Study of the influence of the reprocessing cycles on the final properties of polylactide pieces obtained by injection molding. Polymers 2019, 11, 1908. [CrossRef]

52. Barcík, Š.; Gašparík, M.; Razumov, E.Y. Effect of temperature on the color changes of wood during thermal modification. Cellul. Chem. Technol. 2015, 49, 789-798.

53. Liminana, P.; Garcia-Sanoguera, D.; Quiles-Carrillo, L.; Balart, R.; Montanes, N. Development and characterization of environmentally friendly composites from poly (butylene succinate) (PBS) and almond shell flour with different compatibilizers. Compos. Part B Eng. 2018, 144, 153-162. [CrossRef]

54. Jin, T.x.; Zhou, M.; Hu, S.d.; Chen, F.; Fu, Q.; Fu, Y. Effect of molecular weight on the properties of poly(butylene succinate). Chin. J. Polym. Sci. 2014, 32, 953-960. [CrossRef]

55. Huang, H.X.; Zhang, J.J. Effects of filler-filler and polymer-filler interactions on rheological and mechanical properties of HDPE-wood composites. J. Appl. Polym. Sci. 2009, 111, 2806-2812. [CrossRef]

56. Chun, K.S.; Husseinsyah, S.; Osman, H. Mechanical and thermal properties of coconut shell powder filled polylactic acid biocomposites: Effects of the filler content and silane coupling agent. J. Polym. Res. 2012, 19, 1-8. [CrossRef] 
57. Kajaks, J.; Kalnins, K.; Naburgs, R. Wood plastic composites (WPC) based on high-density polyethylene and birch wood plywood production residues. Int. Wood Prod. J. 2018, 9, 15-21. [CrossRef]

58. Ivorra-Martinez, J.; Manuel-Mañogil, J.; Boronat, T.; Sanchez-Nacher, L.; Balart, R.; Quiles-Carrillo, L. Development and characterization of sustainable composites from bacterial polyester poly(3-hydroxybutyrate-co-3-hydroxyhexanoate) and almond shell flour by reactive extrusion with oligomers of lactic acid. Polymers 2020, 12, 1097. [CrossRef]

59. Ferri, J.M.; Garcia-Garcia, D.; Montanes, N.; Fenollar, O.; Balart, R. The effect of maleinized linseed oil as biobased plasticizer in poly(lactic acid)-based formulations. Polym. Int. 2017, 66, 882-891. [CrossRef]

60. Liminana, P.; Quiles-Carrillo, L.; Boronat, T.; Balart, R.; Montanes, N. The Effect of Varying Almond Shell Flour (ASF) Loading in Composites with Poly(Butylene Succinate (PBS) Matrix Compatibilized with Maleinized Linseed Oil (MLO). Materials 2018, 11, 2179. [CrossRef] [PubMed]

61. Phua, Y.; Chow, W.; Mohd Ishak, Z. Reactive processing of maleic anhydride-grafted poly(butylene succinate) and the compatibilizing effect on poly(butylene succinate) nanocomposites. Express Polym. Lett. 2013, 7. [CrossRef]

62. El-Nabarawy, T.; Petro, N.S.; Abdel-Aziz, S. Adsorption Characteristics of Coal-based Activated Carbons. II. Adsorption of Water Vapour, Pyridine and Benzene. Adsorpt. Sci. Technol. 1997, 15, 47-57. [CrossRef]

63. Çelik, Y.H.; Yalcin, R.; Topkaya, T.; Başaran, E.; Kilickap, E. Characterization of Hazelnut, Pistachio, and Apricot Kernel Shell Particles and Analysis of Their Composite Properties. J. Nat. Fibers 2021, 18, 1054-1068. [CrossRef]

64. Yao, S.-F.; Chen, X.-T.; Ye, H.-M. Investigation of Structure and Crystallization Behavior of Poly(butylene succinate) by Fourier Transform Infrared Spectroscopy. J. Phys. Chem. B 2017, 121, 9476-9485. [CrossRef]

65. John, J.; Tang, J.; Yang, Z.; Bhattacharya, M. Synthesis and characterization of anhydride-functional polycaprolactone. J. Polym. Sci. Part. A Polym. Chem. 1997, 35, 1139-1148. [CrossRef]

66. Chandra, R.; Rustgi, R. Biodegradation of maleated linear low-density polyethylene and starch blends. Polym. Degrad. Stab. 1997, 56, 185-202. [CrossRef]

67. Wang, Y.; Ji, D.; Yang, C.; Zhang, H.; Qin, C.; Huang, B. Structure and properties of maleated high-density polyethylene. J. Appl. Polym. Sci. 1994, 52, 1411-1417. [CrossRef]

68. Wu, C.S.; Liao, H.T.; Lai, S.M. Study on the graft reaction of maleic anhydride onto metallocene-based polyethylene-octene elastomer. Polym.-Plast. Technol. Eng. 2002, 41, 645-661. [CrossRef]

69. Yu, Z.Z.; Ou, Y.C.; Qi, Z.N.; Hu, G.H. Toughening of nylon 6 with a maleated core-shell impact modifier. J. Polym. Sci. Part. B Polym. Phys. 1998, 36, 1987-1994. [CrossRef]

70. Bledzki, A.K.; Reihmane, S.; Gassan, J. Properties and modification methods for vegetable fibers for natural fiber composites. J. Appl. Polym. Sci. 1996, 59, 1329-1336. [CrossRef]

71. Kim, H.S.; Kim, H.J.; Lee, J.W.; Choi, I.G. Biodegradability of bio-flour filled biodegradable poly(butylene succinate) biocomposites in natural and compost soil. Polym. Degrad. Stab. 2006, 91, 1117-1127. [CrossRef]

72. Chen, R.y.; Zou, W.; Zhang, H.c.; Zhang, G.z.; Yang, Z.t.; Jin, G.; Qu, J.p. Thermal behavior, dynamic mechanical properties and rheological properties of poly(butylene succinate) composites filled with nanometer calcium carbonate. Polym. Test. 2015, 42, 160-167. [CrossRef]

73. Chen, R.; Zou, W.; Zhang, H.; Zhang, G.; Qu, J. Crystallization behavior and thermal stability of poly(butylene succinate)/poly(propylene carbonate) blends prepared by novel vane extruder. AIP Conf. Proc. 2016, 1713, 050002. [CrossRef]

74. Song, D.K.; Sung, Y.K. Synthesis and characterization of biodegradable poly(1,4-butanediol succinate). J. Appl. Polym. Sci. 1995, 56, 1381-1395. [CrossRef]

75. Nikolic, M.S.; Djonlagic, J. Synthesis and characterization of biodegradable poly(butylene succinate-co-butylene adipate)s. Polym. Degrad. Stab. 2001, 74, 263-270. [CrossRef]

76. Luo, X.; Li, J.; Feng, J.; Yang, T.; Lin, X. Mechanical and thermal performance of distillers grains filled poly(butylene succinate) composites. Mater. Des. 2014, 57, 195-200. [CrossRef]

77. Balart, J.; García-Sanoguera, D.; Balart, R.; Boronat, T.; Sánchez-Nacher, L. Manufacturing and properties of biobased thermoplastic composites from poly(lactid acid) and hazelnut shell wastes. Polym. Compos. 2018, 39, 848-857. [CrossRef]

78. Liminana, P.; Garcia-Sanoguera, D.; Quiles-Carrillo, L.; Balart, R.; Montanes, N. Optimization of maleinized linseed oil loading as a biobased compatibilizer in poly(butylene succinate) composites with almond shell flour. Materials 2019, 12, 685. [CrossRef] [PubMed]

79. Bendahou, A.; Kaddami, H.; Sautereau, H.; Raihane, M.; Erchiqui, F.; Dufresne, A. Short palm tree fibers polyolefin composites: Effect of filler content and coupling agent on physical properties. Macromol. Mater. Eng. 2008, 293, 140-148. [CrossRef]

80. Gupta, S.; Gupta, G.K.; Mondal, M.K. Thermal degradation characteristics, kinetics, thermodynamic, and reaction mechanism analysis of pistachio shell pyrolysis for its bioenergy potential. Biomass Convers. Biorefin. 2020, 1-15. [CrossRef]

81. Açıalın, K. Pyrolytic characteristics and kinetics of pistachio shell by thermogravimetric analysis. J. Therm. Anal. Calorim. 2012, 109, 227-235. [CrossRef]

82. Lee, S.-H.; Wang, S. Biodegradable polymers/bamboo fiber biocomposite with bio-based coupling agent. Compos. Part. A Appl. Sci. Manuf. 2006, 37, 80-91. [CrossRef]

83. Kim, H.S.; Lee, B.H.; Choi, S.W.; Kim, S.; Kim, H.J. The effect of types of maleic anhydride-grafted polypropylene (MAPP) on the interfacial adhesion properties of bio-flour-filled polypropylene composites. Compos. Part. A Appl. Sci. Manuf. 2007, 38, 1473-1482. [CrossRef] 
84. Montava-Jorda, S.; Lascano, D.; Quiles-Carrillo, L.; Montanes, N.; Boronat, T.; Martinez-Sanz, A.V.; Ferrandiz-Bou, S.; Torres-Giner, S. Mechanical Recycling of Partially Bio-Based and Recycled Polyethylene Terephthalate Blends by Reactive Extrusion with Poly(styrene-co-glycidyl methacrylate). Polymers 2020, 12, 174. [CrossRef] [PubMed]

85. Bautista, Y.; Gozalbo, A.; Mestre, S.; Sanz, V. Thermal Degradation Mechanism of a Thermostable Polyester Stabilized with an Open-Cage Oligomeric Silsesquioxane. Materials 2018, 11, 22. [CrossRef]

86. Shen, D.; Gu, S.; Luo, K.; Wang, S.; Fang, M. The pyrolytic degradation of wood-derived lignin from pulping process. Bioresour. Technol. 2010, 101, 6136-6146. [CrossRef] [PubMed]

87. Hexig, B.; Alata, H.; Asakawa, N.; Inoue, Y. Novel biodegradable poly(butylene succinate)/poly(ethylene oxide) blend film with compositional and spherulite-size gradients. J. Polym. Sci. Part. B Polym. Phys. 2005, 43, 368-377. [CrossRef]

88. Lin, N.; Fan, D.; Chang, P.R.; Yu, J.; Cheng, X.; Huang, J. Structure and properties of poly(butylene succinate) filled with lignin: A case of lignosulfonate. J. Appl. Polym. Sci. 2011, 121, 1717-1724. [CrossRef]

89. Torres-Giner, S.; Montanes, N.; Fenollar, O.; García-Sanoguera, D.; Balart, R. Development and optimization of renewable vinyl plastisol/wood flour composites exposed to ultraviolet radiation. Mater. Des. 2016, 108, 648-658. [CrossRef]

90. Frollini, E.; Bartolucci, N.; Sisti, L.; Celli, A. Poly(butylene succinate) reinforced with different lignocellulosic fibers. Ind. Crop. Prod. 2013, 45, 160-169. [CrossRef]

91. Kiani, H.; Ashori, A.; Mozaffari, S.A. Water resistance and thermal stability of hybrid lignocellulosic filler-PVC composites. Polym. Bull. 2011, 66, 797-802. [CrossRef]

92. Burgada, F.; Fages, E.; Quiles-Carrillo, L.; Lascano, D.; Ivorra-Martinez, J.; Arrieta, M.P.; Fenollar, O. Upgrading Recycled Polypropylene from Textile Wastes in Wood Plastic Composites with Short Hemp Fiber. Polymers 2021, 13, 1248. [CrossRef]

93. Gairola, S.; Gairola, S.; Sharma, H.; Rakesh, P.K. Impact Behavior of Pine Needle Fiber/Pistachio Shell Filler Based Epoxy Composite. In Proceedings of the 2nd International Conference on New Frontiers in Engineering, Science and Technology (NFEST 2019), Kurukshetra, India, 18-22 February 2019.

94. Quiles-Carrillo, L.; Montanes, N.; Garcia-Garcia, D.; Carbonell-Verdu, A.; Balart, R.; Torres-Giner, S. Effect of different compatibilizers on injection-molded green composite pieces based on polylactide filled with almond shell flour. Compos. Part. B Eng. 2018, 147, 76-85. [CrossRef]

95. Alvarez, V.A.; Vázquez, A. Influence of fiber chemical modification procedure on the mechanical properties and water absorption of MaterBi-Y/sisal fiber composites. Compos. Part. A Appl. Sci. Manuf. 2006, 37, 1672-1680. [CrossRef]

96. Tserki, V.; Matzinos, P.; Kokkou, S.; Panayiotou, C. Novel biodegradable composites based on treated lignocellulosic waste flour as filler. Part I. Surface chemical modification and characterization of waste flour. Compos. Part. A Appl. Sci. Manuf. 2005, 36, 965-974. [CrossRef]

97. Gassan, J.; Bledzki, A.K. The influence of fiber-surface treatment on the mechanical properties of jute-polypropylene composites. Compos. Part. A Appl. Sci. Manuf. 1997, 28, 1001-1005. [CrossRef]

98. Tolga, S.; Kabasci, S.; Duhme, M. Progress of disintegration of polylactide (PLA)/poly(butylene succinate) (PBS) blends containing talc and chalk inorganic fillers under industrial composting conditions. Polymers 2021, 23, 10. [CrossRef]

99. Zhao, J.H.; Wang, X.Q.; Zeng, J.; Yang, G.; Shi, F.H.; Yan, Q. Biodegradation of poly(butylene succinate) in compost. J. Appl. Polym. Sci. 2005, 97, 2273-2278. [CrossRef]

100. Mwaikambo, L.Y.; Martuscelli, E.; Avella, M. Kapok/cotton fabric-polypropylene composites. Polym. Test. 2000, 19, 905-918. [CrossRef]

101. Mathew, A.P.; Oksman, K.; Sain, M. Mechanical properties of biodegradable composites from poly lactic acid (PLA) and microcrystalline cellulose (MCC). J. Appl. Polym. Sci. 2005, 97, 2014-2025. [CrossRef]

102. Kumar, R.; Yakubu, M.K.; Anandjiwala, R.D. Biodegradation of flax fiber reinforced poly lactic acid. Express Polym. Lett. 2010, 4. [CrossRef]

103. Puchalski, M.; Szparaga, G.; Biela, T.; Gutowska, A.; Sztajnowski, S.; Krucińska, I. Molecular and Supramolecular Changes in Polybutylene Succinate (PBS) and Polybutylene Succinate Adipate (PBSA) Copolymer during Degradation in Various Environmental Conditions. Polymers 2018, 10, 251. [CrossRef]

104. Gabara, W.; Porejko, S. Grafting of maleic anhydride on polyethylene. I. Mechanism of grafting in a heterogeneous medium in the presence of radical initiators. J. Polym. Sci. Part. A-1 Polym. Chem. 1967, 5, 1547-1562. [CrossRef]

105. Muthuraj, R.; Misra, M.; Mohanty, A.K. Injection Molded Sustainable Biocomposites From Poly(butylene succinate) Bioplastic and Perennial Grass. ACS Sustain. Chem. Eng. 2015, 3, 2767-2776. [CrossRef] 